\title{
EL YACIMIENTO ARQUEOLOGICO DE CERCADILLA: AVANCE DE RESULTADOS
}

\author{
Rafael HIDALGO PRIETO \\ Pedro MARFIL RUIZ \\ Universidad de Córdoba
}

\section{Resumen}

En este artículo presentamos un avance de resultados de la Excavación Arqueológica que se desarrolla en los terrenos de Cercadilla en Córdoba. Puede destacarse la constatación de la existencia en el yacimiento de restos de un palatium construido a fines del s. III o inicios del IV dC. y en uso hasta el s. V dC.

El palatium se articula en torno a un criptopórtico con pasillo superior semicircular de $109 \mathrm{~m}$. de diámetro, con aulas triconques en los extremos, desde el que se distribuye el paso a una serie de edificios radiales. El espacio en exedra circunscribe una plaza central cerrada por un cuerpo de acceso con entrada torreada. Las características de monumentalidad y complejidad del conjunto tardorromano, el predominio de plantas basilicales y la inexistencia de zonas de hábitat doméstico nos llevan a plantear como hipótesis su carácter público y su adscripción al tipo palatium como centro administrativo durante el s.IV.

\section{Summary}

In this paper we present the preliminary results of the 1991-92 digging season in Cercadilla (Cordoba). We should emphasize the discovery in this site of the remains of a palatium built towards the end of the third or the beggining of the fourth century A.D. It seems to have remained in use well into the fifth century A.D.

The palatium was built around a semicircular cryptoporticus with a diameter of $109 \mathrm{~m}$., with triconch halls at both ends. The cryptoporticus gives access towards a series of radial buidings. The whole complex delimites a huge semicircular square, closed at its front with a rectilinear building with towered entrance reminiscent of military architecture. 
The grandiosity of the building scheme, the complexity and scale of this Late Roman monument, the dominance of basilical ground plans, and the absence of domestic quarters, leads us to put forward three main hypotheses: its public character, its relationship with the well-known palatium type, and its function as an administrative and representative complex during the fourth century A.D.

El yacimiento de Cercadilla, aunque inscrito en el trazado urbanístico de la Córdoba actual, se sitúa en una zona periférica. Es más, el hecho de encontrarse en su mayor parte dentro de terrenos ocupados por el trazado ferroviario, desde finales del siglo XIX, permitió su conservación frente a la expansión urbana.

Con respecto al recinto de Colonia Patricia el yacimiento se encuentra a extramuros y ubicado al Noroeste de la ciudad, a $700 \mathrm{~m}$. de él y a $750 \mathrm{~m}$. de la puerta más cercana. De esta zona era ya conocido su uso como necrópolis, de la que como ejemplo podemos citar los enterramientos detectados por Samuel de los Santos (1955:10,42-43 y fig.1) poco más al Norte de la necrópolis excavada ahora por nosotros mismos. En cuanto a la alusión historiográfica a la presencia de vestigios arqueológicos en la zona, contamos también con la noticia aportada por José María de Navascués quien en 1921 (NAVASCUES, 1922), al realizarse la ampliación de la línea férrea a doble vía, localizó el criptopórtico y excavó parte de sus niveles de colmatación interior. Dado al escaso espacio excavado, lógicamente no pudo llegar a intuir la entidad del edificio en el que se encontraba.

En lo que se refiere a los trabajos recientemente realizados, la primera excavación arqueológica tiene su origen en la aparición de restos arqueológicos de carácter monumental en los terrenos ocupados por la antigua estación de Cercadilla, en Abril de 1991, durante los trabajos de soterramiento de la Red Arterial Ferroviaria de Córdoba.

Una primera fase de excavación se desarrolló entre los días 20 de Mayo y 20 de Agosto de 1991, dirigida por el arquéblogo provincial, A. Ibáñez Castro, y contando con la participación directa de miembros del Seminario de Arqueología de la Universidad de Córdoba. Sus objetivos eran la delimitación espacial del yacimiento así como su adscripción cultural y cronológica.

Tras esta primera actuación y en función de los resultados obtenidos, la Consejería de Cultura de la Junta de Andalucía convocó una comisión científica que valorase la importancia de los restos de cara a su conservación. Posteriormente, y en función del carácter excepcional del monumento, las instituciones implicadas en la creación de la nueva estación ferroviaria designaron una Comisión de Integración cuyo objetivo sería la elaboración de un proyecto en el que se integrasen las estructuras arqueologicas en la futura estación.

A inicios del mes de Diciembre comenzó una segunda fase de trabajo de campo, dirigida por quienes suscriben estas líneas, en calidad de miembros del mencionado 
Seminario de Arqueología, y promovida con carácter de urgencia por la Consejería de Cultura de la Junta de Andalucía. Para la realización de esta nueva fase contamos con un amplio equipo técnico (1), acorde con la entidad del yacimiento, su extensión y el escaso tiempo de excavación de que se dispone.

El espacio objeto de la intervención está circunscrito por dos ejes longitudinales que delimitan el área que ocupará la futura estación y haz de vías, conformando un pasillo de $700 \mathrm{~m}$. de longitud y $80 \mathrm{~m}$. de anchura. La excavación en dicha "playa de vías" está prevista hasta el mes de Mayo de 1992, compaginándose con algunas actuaciones en la zona Norte del yacimiento, y su objetivo prioritario es la obtención del mayor volumen posible de información referente al conunto monumental tardorromano, así como la delimitación de periodos y fases de ocupación.

El yacimiento no se restringe únicamente al complejo monumental tardorromano, por otra parte la fase más importante, ya que la evidencia arqueológica ha permitido comprobar la existencia de ocupación humana en distintos períodos y fases.

Los restos de cultura material más antiguos consisten en algunos elementos arquitectónicos, en concreto tambores de fuste de columna estriados y parte de una comisa con revestimiento de estuco, así como una basa de considerables dimensiones, elaborados en arenisca y de tipología tardorrepublicana, en parte reutilizados en construcciones posteriores, que probablemente corresponden a algún edificio desmantelado para la realización de dichas construcciones.

También se ha documentado la presencia de al menos una incineración en uma de tradición indígena con decoración a bandas, posiblemente parte de la necrópolis altoimperial localizada en las inmediaciones del yacimiento.

La construcción de una villa, en la que existen al menos tres fases de remodelación, y cuya datación provisional oscila entre mediados del s.II e inicios del III d.C., abre una nueva etapa de ocupación de este espacio. El proceso de investigación en este edificio ha permitido documentar la presencia de la pars urbana en la que se conservan los pavimentos musivos, siempre constituidos por mosaicos geométricos bícromos o polícromos con esquema de husos tangentes, cuadrilobulos de peltas, líneas de peltas enlazadas y rosáceas. Los datos aportados por la excavación indican la posibilidad de que su arrasamiento coincidiese con la construcción del complejo monumental tardorromano.

Esto último supuso sin duda una fuerte remodelación del espacio. La búsqueda de soluciones de adecuación del terreno pasó por el arrasamiento de las estructuras

(1) Este equipo técnico está compuesto por:

ARQUEOLOGOS: F. Alarcón, J.M. Bermúdez, S. Carmona, I.Elejalde, E. Ferrer, C. Fuertes, E. García, J.M. Gener, M. González, J.M. Hita, A. Montejo, M. Moreno, J.F. Murillo, F. Penco, M. Puentedura, M.D. Ruiz, F. Sibón, A. Ventura, J.C. Vera, A. Zamorano.

RESTAURADOR: C. Costa.

AYTE. RESTAURACION: J. Martínez.
ANTROPOLOGA: M.J. Casas

AYTE. ANTROPOLOGIA: R. Font, M.C. Blanes. ZOOLOGO: J.C. Esteban.

ARQUITECTO TECNICO: F. Beltrán.

INFORMATICA: M.D. Luna.

DOCUMENTALISTA: M.C. Márquez.

DIBUJANTES: M.A. Carmona, J. Castaño, M.D. de Haro, M.R. Herrero, D. Mancheño, A. Pardo, M.C. Sampedro 
preexistentes, así como por la creación de un aterrazamiento artificial que salvase el desnivel natural. Esta plataforma artificial genera un nuevo espacio constructivo perfectamente adecuado para la cristalización material del diseño arquitectónico.

Los datos cronológicos referentes al inicio de la construcción del monumento arrojan como índice provisional una datación que gira en torno al último tercio del s. III, principios del IV. Asimismo tenemos constancia de la pervivencia del uso del monumento como tal durante el s. V, observándose la presencia de elementos posteriores que evidencian una reocupación en precario de las estructuras.

Creemos importante reseñar la reutilización de uno de los edificios, le aula trichora Norte, como lugar de culto cristiano. Debido a que su diseño es muy similar al de las basílicas paleocristianas, su planta se reaprovecha y adapta dividiéndola en tres naves longitudinales y convirtiéndola en centro de culto cristiano. Posiblemente nos encontramos ante la basílica tardoantigua de San Acisclo, que pervive aún en época mozárabe. La localización de dicha basílica ha sido causa de intensos debates eruditos en la historiografía cordobesa (2).

Samuel de los Santos Gener (1955) la ubicó en los terrenos del antiguo cortijo de Chinales, al Oeste de la ciudad. Sus excavaciones en la zona de referencia documentaron la existencia de restos estructurales de considerable entidad $(75 \times 50 \mathrm{~m}$.), así como elementos arquitectónicos visigóticos (3), lo que le llevó a pensar, junto a su ubicación, que se hallaba ante los restos de la basílica mencionada por las fuentes. La metodología de la época y principalmente los condicionantes impuestos por el proceso de construcción del momento, impidieron al admirado maestro obtener datos más precisos acerca de la imbricación estratigráfica de los restos estructurales y su relación con los elementos arquitectónicos visigodos exhumados. No dudamos de la posible adscripción de este edificio o complejo de edificaciones a la época visigoda (4), aunque consideramos que su identificación con la Basílica de San Acisclo no puede llevarse, hoy por hoy, más allá de la hipótesis de trabajo fruto de un momento histórico en el desarrollo de la arqueología cordobesa.

San Isidoro (FLOREZ, 1901) nos informa acerca de su existencia ya en época visigoda al referirse a la incursión del rey Agila contra los cristianos hispanorromanos cordobeses en el $550 \mathrm{dC}$., en concreto alude a la profanación de la basílica de San Acisclo al usarla como establo.

(2) Sánchez de Feria (1772:359) la sitúa en el Convento de los Mártires, frente al Molino de Martos. Ramírez de Arellano (1973:T.II-92) creía que se ubicaba en Santa Clara.

(3) Se hallaron cuatro fustes de columna, un capitel visigodo y una basa en la zona en donde se localizaron las estructuras, así como dos placas decorativas de mármol, un salmer decorado, un capitel visigodo, una ménsula visigoda y una basa de piedra caliza en sus inmediaciones (SANTOS GENER, 1955:35).

(4) En los cercanos llanos o explanadas de Vista Alegre, también documentó D. Samuel de los Santos la presencia de restos de época visigoda y mozárabe, en concreto, varios sarcófagos, y una lápida funeraria que presenta el nombre de Acisclus, lo que en principio le hizo pensar que se trataba de la Basílica (SANTOS GENER, 1955:29-30). 
La Basílica debía presentar una entidad arquitectónica considerable -coincidiendo en ello con el edificio de Cercadilla-; se trataba de un edificio perfectamente defendible y con capacidad para albergar y abastecer a una comunidad numerosa. Esto se desprende de la información aportada por el texto del Ajbar-Maŷmü' $a$ (ARJONA CASTRO, 1982: 13-14) al referirse a la conquista de la ciudad en el 711, cuando narra la resistencia del gobemador visigodo y sus tropas en la Basílica de San Acisclo durante los tres meses en que permanecieron sitiados por las fuerzas de Mugith (5).

En relación con este acontecimiento-se ha intentado sustentar la afirmación de que la Basílica de S. Acisclo se ubicaba en las cercanías del actual cementerio de la Salud, al Suroeste de la ciudad, dado que el gobernador visigodo y sus tropas salieron del recinto amurallado por la puerta de los perfumistas, por lo que se ha deducido que la basílica debía estar en las cercanias de dicha puerta. Sin embargo la razón de la salida de las tropas visigodas por la puerta de Sevilla responde simplemente a la lógica urbana, ya que se encontraba junto al muro Oeste del palacio del gobernador y los musulmanes habían penetrado en la ciudad por la puerta de la Isla (Bab al Yazirat).

San Eulogio nos habla de esta basílica como importante enclave cristiano, junto a la que existía un centro de instrucción (6), y nos confirma la existencia del sepulcro del mártir en la Basílica.

Durante los trabajos de excavación en el yacimiento de Cercadilla y en las cercanías del lado Norte del aula triconque Norte, se documentó la existencia de un enterramiento mozárabe que presentaba como cubierta una lápida reutilizada. Se trataba de la lápida funeraria del obispo hispanorromano Lampadius (7), y aportaba como fecha de su muerte el año 549. Sin duda la losa debía proceder de un lugar cercano, o del mismo edificio reutilizado. Su datación, 549 dC., coincidente con la razzia de Agila y la profanación de la Basílica de San Acisclo, y el hecho de que el difunto sea un obispo, nos lleva a pensar en la posibilidad de que este edificio en sí mismo o junto a las aulas basilicales cercanas, pueda identificarse con la Basílica de San Acisclo. Es más, la reutilización mozárabe de este espacio y del área de necrópolis circundante hasta al menos el s. XI, refuerzan tal hipótesis de trabajo. Por otra parte, su situación al Oeste de la ciudad coincide con la información aportada por las fuentes.

A esta Basílica se asocia una necrópolis cristiana, posiblemente martirial, de la que se han excavado en la actualidad cuarenta enterramientos de tipología muy homogénea (fig. 8), orientados siempre hacia el Este con una única excepción. El cuerpo se deposita siempre en posición decúbito supino con los brazos flexionados sobre tórax o abdomen,

(5) Ya existía un precedente histórico, Hermenegildo se refugia también en una iglesia cordobesa en el 584 (RODRIGUEZ NEILA, 1988:532).

(6) En San Acisclo fueron instruidos el presbítero Perfecto (martirizado en el 850), el levita Sisenando ( $m$. en el 851 ), el diácono Pablo ( $m$. en el 851) y el prebítero Anastasio ( $m$. en el 853), y recibieron sepultura Perfecto, Sisenando, María (m. en el 851, se conservó allí su cabeza) y Argimiro (856). (S.Eul., Mem. de los Santos).

(7) Se conoce otro obispo Lampadius asistente al I Concilio de Toledo del año $400 \mathrm{dC}$. (ORLANDISRAMOS, 1986). 
sin ajuar alguno, sobre tierra apisonada y dentro de una cista de sillarejos -en escasas ocasiones de ladrillo- trabados con ripio suelto y con la cubierta generalmente a base de lajas irregulares de gran tamaño. Estos enterramientos se disponen en su mayoría en torno a la basílica cristiana y dos de ellos en el interior.

Por otra parte, en el sector Oeste del yacimiento se ha documentado también un amplio conjunto de estructuras de habitación de Epoca Medieval Islámica, pertenecientes a uno de los arrabales de la Córdoba califal, en el que se ha delimitado parte del trazado viario y del parcelario antiguo, así como la distribuión de los espacios de habitación. Posiblemente este arrabal se extendería hasta el extremo Este del yacimiento, como demuestra la presencia de restos de una muralla de arrabal.

En cuanto al monumento tardorromano (fig. 3, lám.1) hemos de decir que se organiza en torno a un criptoportico (8) semicircular orientado hacia el Este y que alcanza al interior $109 \mathrm{~m}$. de diámetro máximo. El paso al recinto se realiza a través de un cuerpo de acceso rectangular, conservado casi en su totalidad a nivel de cimientos, que cierra la exedra trazada por el citado criptopórtico. En su zona central se dispone el acceso, en un espacio de diez metros y medio de ancho flanqueado por dos torreones semicirculares. Los contrafuertes localizados en la zona de ingreso nos llevan a plantear la posibilidad de que el pasillo de entrada estuviese cubierto por una bóveda de cañon. Aunque desconocemos la funcionalidad de los espacios circunscritos por los muros de acceso, sabemos que contaban con un pavimento de picadura de arenisca y cubierta de tégulas. Tras franquear la entrada al edificio se accede a un pasillo porticado, paralelo al cuerpo de acceso, desde el que se realiza el paso al criptopórtico a través de sus dos extremos.

En el espacio de grandes dimensiones circunscrito por la exedra y los muros de cierre se han detectado, como ya hemos referido, los restos de una villa anterior, este sector fue arrasado en su mayor parte en un momento previo al inicio de la excavación hasta un nivel muy inferior al correspondiente al del pavimento original del monumento, por lo que la información con que contamos es parcial; no obstante, la ausencia de cimentaciones que pudieran ser adscritas al monumento nos lleva a considerar la posibilidad de que aquí existiera un amplio espacio abierto a modo de jardín o plaza central (9). Por otra parte, en la zona no arrasada no se ha localizado resto alguno de pavimento constructivo, con lo que muy probablemente el suelo sería de tierra apisonada.

En lo que al trazado de la exedra se refiere, como ya hemos dicho, se consigue mediante la construcción de un criptoportico en sigma, cuya bóveda alcanza 4,40 m. de ancho y $3,90 \mathrm{~m}$. de altura, y constituye la solución arquitectónica aportada para resolver el desnivel natural del terreno. En esta zona -tercera terraza del río Guadalquivir- el terreno desciende bruscamente hacia el Sur, ante lo cual la construcción del criptopórtico

(8) Sobre el particular confróntese la obra de Martin (1972) con abundantes paralelos.

(9) Al igual que ocurre en el templo de la Dea Caelestis en Dugga donde, según Gianna Dareggi (1990:200), el espacio circunscrito por el pórtico semicircular estaría ocupado por un jardín con árboles. 
supone la creación de una gran terraza artificial que permite la disposición del monumento orientado al Este, hacia la ciudad. Esta hipotesis se confirma por los datos aportados tanto por la técnica constructiva como por la estratigrafía; en lo que a técnica se refiere, se ha demostrado que la cota de la base de la cimentación de los muros desciende considerablemente de Norte a Sur, hasta alcanzar el terreno geológico, sobre el que apoyan, adoptando así una función contenedora de los aportes antrópicos que la estratigrafía ha permitido observar y cuya finalidad es homogeneizar la superficie de la citada terraza artificial.

El criptoportico presenta dos accesos retranqueados en sus laterales, sin que se haya detectado ninguno más en la mitad de su trazado visible en la actualidad; tan sólo se ha localizado un pequeño acceso secundario que, por otra parte, corresponde a una reforma funcional del sector sur de la galería. Sí existe una serie de lucemarios abocinados, en la zona en la que aún se conserva todo el alzado, equidistantes a 2,40 m. Estos sólo se interrumpen en el espacio correspondiente al eje de simetría de la exedra, donde se sustituyen por una bóveda de crucería.

$\mathrm{Al}$ acceder al criptoportico se produce un considerable descenso de nivel que se salva mediante escaleras dispuestas en los accesos en recodo, de las que hasta el momento tan solo se ha localizado parte de la cimentación de caementicium de la dispuesta al Sur. En el resto del espacio excavado el pavimento original estaba constituido por una capa de cal sobre un lecho de arena de río de $10 \mathrm{~cm}$. de potencia, que apoya sobre los niveles geologicos, excavados por un canalillo de drenaje dispuesto en el centro (10).

Sobre la galería semisubterránea, que sobresale poco más de medio metro del nivel de suelo de la plaza central, se sitúa un pasillo pavimentado con opus caementicium desde el que se realiza la distribución del paso hacia los distintos edificios circundantes y que originalmente estaría porticado, aunque hasta el momento no se ha localizado resto alguno de su cubrición (11).

La zona superior del criptopórtico, ocupada por la galería de ventanas, funcionaría a modo de podium corrido sobre el que se dispone el citado pasillo. El acceso desde la plaza al pasillo posiblemente se realizaría mediante una escalinata situada lógicamente en el eje de simetría de la exedra; precisamente en este lugar desaparece la galería de ventanas, como ya se dijo más arriba, aunque no se ha localizado resto alguno de la cimentación de tal acceso.

(10) En los niveles de reocupación del criptopórtico, pertenecientes a un momento en el que el edificio ha dejado de usarse con su funcionalidad original, se ha localizado un depósito de elementos metálicos, posiblemente fruto del saqueo del edificio, entre los que destaca la presencia de algunas letras de bronce dorado (lám. 4) posiblemente relacionadas con la inscripción fundacional del monumento. El escaso número de letras recuperadas y la ausencia del soporte impiden por el momento cualquier tipo de interpretación de la inscripción en cuestión.

(11) Una idea aproximada de cómo debió ser este pasillo porticado se puede conseguir en base a las representaciones arquitectónicas en pintura mural de la casa de Lucrecio Fronto en Pompeya (SWOBODA, 1924:lám. Ic), las del museo de Nápoles (SWOBODA, 1924:lám.II y III), algunas de las representaciones del Salterio de Utrech (DUVAL, 1965) y en base a las reconstrucciones hipotéticas de algunas construcciones como el pórtico en exedra de la villa Adrianea en Tívoli (MIELSCH, 1987:fig.78). 
En la cabecera de la exedra y perfectamente centrada con respecto a su eje de simetría se dispone un aula basilical de 22,2 m. de anchura y $48,5 \mathrm{~m}$. de longitud, coronada por un ábside de 16,2 m. de diámetro medio (fig. 4). En el exterior presenta una serie de contrafuertes equidistantes a $2,4 \mathrm{~m}$. que, siguiendo el modelo del aula imperial de Tréveris (KRAUTHEIMER, 1967:1ám.1), muy posiblemente se desarrollarían en alzado como arquerías ciegas en las que se dispondrían las ventanas. Sobre la superficie de arrasamiento del muro lateral Norte se dispone una acequia excavada en el caementicium, lo que demuestra que al menos en Epoca Medieval Islámica este edificio estaba destruido prácticamente en su totalidad. No poseemos por el momento dato alguno sobre su pavimiento o niveles de abandono ya que los trabajos efectuados aquí se han limitado a la definición de la planta arquitectónica; sí sabemos, por otra parte, que en su interior y junto al muro lateral Norte se dispone una pileta de opus signinum asociada a un canalillo de tégulas y ladrillos.

Al Sur de éste encontramos otro edificio, también de planta basilical y de $26,8 \mathrm{~m}$. por 14,3 m. (lám.2). El eje de simetría coincide con el centro del semicírculo trazado por el criptoportico, con el que conecta. A pesar de que se encuentra arrasado hasta nivel de cimientos, puede pensarse que su acceso se articulaba a través del pasillo situado sobre el criptopórtico.

Al Norte del edificio que acabamos de describir se dispone otro que también conecta con el criptopórtico y al que igualmente se accedería desde el pórtico superior. Su orientación varía con respecto a los dos anteriores ya que en este caso el centro del eje se sitúa en la zona de acceso al monumento. Se trata de una construcción de planta central, casi perfectamente cuadrangular, con ábsides en cabecera y laterales, de los que destaca el situado en el lado Sur ya que se ve alterado por un refuerzo cuyo origen debe estar relacionado con la contención de los empujes Norte-Sur, motivados por el buzamiento de la paleotopografía. El espacio interno del edificio está compartimentado por una serie de muros dispuestos de forma ligeramente asimétrica con respecto a los ábsides exteriores, y que posiblemente constituyen la cimentación de la columnata que sustentaría la cubierta abovedada, de forma que, mientras los apoyos de las columnas estuvieran asegurados, no debía importar mucho la disposición simétrica de los muros de su cimentación.

Al Sur de este edificio se dispone otro organizado en tomo a una estructura circular a la que se le adosan tres exedras. La excavación de este sector está demostrando que el edificio no se encuentra exento sino que se adosa mediante un corredor al situado inmediatamente al Norte (lám.2). Tanto este edificio como el anterior, se encontraban arrasados hasta nivel de cimientos cuando se inició la excavación, por lo que ha sido imposible recuperar dato alguno sobre pavimentos, nivel de abandono, etc.

Al Norte de los edificios que acabamos de describir y al Sur del aula central se han localizado algunas estructuras pertenecientes a un edificio del que por el momento desconocemos gran parte de su planta. Sí sabemos, al menos, que este edificio se organiza 
de forma radial con respecto al criptoportico, como ocurre en los casos anteriores, y que su eje de simetría problablemente se dispone también en el acceso al monumento. Cabe destacar que lạ estructura más alejada correspondiente a esta construcción se sitúa a poco menos de doscientos metros con respecto al acceso al conjunto.

Por otra parte, conectando también con el pórtico en exedra y a pocos metros al Norte del aula central se dispone otro edificio del que apenas contamos con un muro en planta, y del que sí conocemos el acceso, que se realizaría a través de un vano localizado en el pórtico (12).

Junto a los accesos en recodo del criptoportico se disponen sendos edificios rectangulares con cabecera triconque. De ellos solo se ha excavado el situado al Norte (fig.5, lám. 3), en el que se detecta una importante reocupación y readaptación funcional. En ambos casos el espacio interno aparece dividido mediante dos muros transversales, en tres estancias de dimensiones similares. El acceso a estos edificios se encontraría en los extremos del pórtico en exedra.

Ante el acceso al monumento se dispone una estructura longitudinal coronada en ábside al Sur, cuya orientación difiere de la marcada por la exedra monumental y cuyo extremo Sur coincide con el eje de simetría del monumento. La excavación actualmente en curso ha permitido constatar la presencia de dos exedras, simétricas y afrontadas, dispuestas en el centro del corredor longitudinal. La técnica edilicia aplicada a este edificio es similar a la de todo el conjunto, empleándose opus caementicium en la construcción de los muros aunque sin el revestimiento de opus mixtum, habitual en el resto de las construcciones. El pavimento interior, situado en una cota sensiblemente inferior con respecto al nivel de suelo exterior, está constituido por una doble hilada de mampuesto irregular trabado con mortero de cal. Un primer análisis de la planta de esta construcción, permite plantear una posible función hidráulica para la misma (13); aunque carece de un verdadero pavimento impermeable, probablemente el detectado sería el rudus que nunca llegó a cubrirse con el opus signinum, quedando pues la construcción inacabada, siendo quizás amortizada por una construcción de la que hemos podido documentar cimentaciones de opus caementicium.

Los datos aportados por la excavación dejan patente la uniformidad del monumento en lo que a técnica constructiva se refiere. Cabe destacar el predominio casi absoluto del opus mixtum y opus caementicium sobre el opus quadratum, variando sustancialmente la tradición constructiva de Colonia Patricia donde los sillares de arenisca y caliza constituyen el material constructivo básico de los edificios conocidos. En la mayoría de

(12) Entre este edificio y el aula central se ha localizado otro vano, cuya función no es la de permitir el acceso a uno de los edificios radiales, sino a uno de los espacios intermedios. Esto nos hace plantear la posibilidad, a demostrar por la excavación, de que en este espacio exista algún edificio al que indirectamente también se accediera desde el pórtico.

(13) Estructuras hidráulicas con diseño similar al que hasta ahora conocemos en Cercadilla, aparecen en algunas villas como la de Herculano (McKAY, 1975:fig. 42) o la de Grassi (BEDON ET ALII, 1988:354), esta última de dimensiones mucho más reducidas. 
los casos la cimentación de los muros es de opus camenticium, sobre el que se dispone una hilada de nivelación a base de sillares y alzado de caementicium, con revestimiento de mixtum a base de vittatum y testaceum (14).

El método empleado para la realización de este tipo de estructuras es también muy homogéneo. Para construir la cimentación se trazan zanjas con las dimensiones exactas que tendrán los muros, aprovechando la consistencia del terreno, y se vierte directamente en ellas el caementicium, sin que sea necesario aporte alguno de sedimento. Como ya se ha dicho, sobre la cimentación se suele disponer una hilada de nivelación a base de sillares, en la que apoya el muro con núcleo de caementicium y revestimiento de vittatum mixtum. El nivel de suelo usado en el momento de la construcción coincide con la base de la hilada de nivelación y el inicio de la cimentación de caementicium, constituyendo un horizonte caracterizado por la presencia de un estrato de potencia irregular con restos de argamasa, ladrillos, arenisca descompuesta, etc. Cuando la ejecución de los muros ha concluido se aporta sedimento sobre el horizonte de construcción, con el fin de nivelar la terraza artificial coṇtenida por las estructuras, y sobre éste se dispone finalmente el pavimento. En consecuencia, en función de la cota de inicio de cimentación, siempre encontramos parte del revestimiento de vittatum mixtum por debajo del nivel de pavimento.

Por otra parte, cabe destacar la ausencia generalizada en el estado actual de la excavación de restos de decoración arquitectónica como pavimentos musivos, estuco, mármol, etc., si bien, por el momento prácticamente la totalidad del espacio excavado ha correspondido a sectores del complejo arrasados a nivel de cimientos.

En lo que a cronología se refiere, los datos de mayor fiabilidad con los que contamos son los aportados por un sondeo estratigráfico situado junto a la galería de ventanas del criptopórtico, en una zona donde la base del muro se proyecta y se realiza aporte de sedimento. Los materiales recuperados (15) aportan una datación provisional para la fundación del monumento en tomo al último tercio del s. III o inicios del s.IV, permaneciendo en uso al menos hasta mediados del s.V. Su abandono se produce posiblemente a fines del siglo $\mathrm{V}$ aunque se observa la presencia de elementos posteriores que evidencian la reocupación de las estructuras. La reutilización y reordenación de parte del monumento como centro de culto cristiano y necrópolis se constata ya mediados del s. VI, en concreto a partir del año 459, momento en el que se data la citada lápida del obispo Lampadio, aparecida en un enterramiento junto a la trichora Norte, perdurando al menos hasta el s. $\mathrm{XI}$, como demuestra la presencia de algunas lápidas mozárabes de este momento.

(14) La alternancia de hiladas de sillarejo y ladrillo no sigue un esquema homogéneo en los distintos paramentos. En lo que respecta a las dimensiones de los sillarejos, son bastante irregulares oscilando en torno a los $20 \mathrm{~cm}$. de lado, por su parte, los ladrillos, en parte reutilizados, se agrupan en tres módulos diferentes:

$28-30 \times 15-17 \times 4-6 \mathrm{~cm} .=78,5 \%$

$42-44 \times 30-31 \times 6-6,5 \mathrm{~cm} .=14,28 \%$

$28,5 \times 28,5 \times 7 \mathrm{~cm} .=3,57 \%$

(15) En su mayoría cerámica africana del tipo $\mathrm{C}^{2}$ con predominio de la forma hayes 50. 
La concepción arquitectónica del edificio, tan singular como eficaz en su desarrollo, nos plantea serios problemas de cara a la adscripción funcional del complejo. A nivel formal no se conoce ningún edificio cuyo diseño coincida con el que aquí nos ocupa. Sí conocemos edificios organizados en torno a una exedra, principalmente villas como las de Tettingen (SWOBODA, 1924:fig. 26) o Montmaurin (FOUET, 1983: fig. 23) o palacios como el de Antíoco en Constantinopla (DUYURAN, 1952 y 1953) (16). El diseño en exedra se aplica también a otros edificios (vid. RAKOB, 1974), de menor interés para el caso que nos ocupa, como ninfeos, en especial el de Zaguan, templos como el de la Dea Caelestis en Dugga y santuarios como el de Isis y Serapis en Roma.

Por otra parte, varios son los aspectos que complican y dificultan la interpretación del monumento, entre los cuales cabe referir sus enormes dimensiones, su avanzada cronología y la complejidad de su planta. Si se lleva a cabo el análisis tipológico individualizado de los edificios que constituyen el conjunto y de la distribución de espacios, se puede comprobar que los diseños aplicados -básicamente aulas basilicales y triconques- responden a modelos bien conocidos en la arquitectura romana.

En lo que respecta a las aulas basilicales, por el momento se han excavado dos edificios adscribibles a esta categoría. En ambos casos, y en función de la información con que contamos en la actualidad, sigue el esquema de nave única con ábside en la cabecera. Los edificios mejor conocidos que responden a este mismo planteamiento son el aula palatina de Tréveris (KRAUTHEIMER, 1967:117), fechada entre los años 305312 d.C., el aula basilical del palacio de Majencio en la vía Apia (PISANI-CALZA, 1976:129 y lám.XLVI), fechado a inicios del s. IV, la construida en Piazza Armerina (CARANDINI ET ALII, 1982) entre los años 320-330 d.C., el aula de Metz (REUSCHMYLIUS, 1949), también del s.IV, la del palacio de Galerio en Gamzigrad (SREJOVIC ET ALLII, 1983), de principios del s. IV, la del palacio del Sessorium en Roma (COLINI, 1965:164), de nuevo de principios del s.IV, la de Junio Basso, construida en tomo al 330 d. C. (KRAUTHEIMER, 1967:126), y la del palacio de la isla de Meleda (CAGIANO, 1986c), datada en el 489 d.C. (17).

(16) Este complejo palacial, de concepción muy similar al conjunto de Cercadilla aunque de dimensiones mucho menores, fue propiedad de Antíoco, praepositus sacri cubiculi -chambelán de época tardorromana en Oriente-, personaje de gran autoridad durante los últimos tiempos de Arcadio y la juventud de Teodosio II. Según Lise Bek (1983:96-97) se le expropia a su propietario cuando éste cae en desgracia con el emperador en el año 436, entre 414 y 421 para Paolo Verzone (1976:41), y queda en poder de la corte para uso oficial, pasando más tarde a constituir la domus augustae Pulcheriae. La acusación contra Antíoco se basó en que éste se comportaba como un emperador, por lo que es lógico pensar que el diseño arquitectónico de su vivienda seguía modelos imperiales. Por otra parte, la cronología de este edificio, principios del s. V, hace imposible plantear la influencia de su diseño sobre el de Cercadilla, que si existiera sería a través de un modelo que desconocemos o en sentido contrario, de occidente hacia oriente, constituyendo así un importante nexo entre la arquitectura tardorromana occidental y la que, en progresiva diferenciación, se está generando en la pars orientis, en el proceso de formación de las bases de la cultura bizantina.

(17) Este palacio, situado en una isla frente a la costa yugoslava, plantea especial interés gracias a su estado de conservación. El edificio se organiza en función de una gran sala de recepción de planta basilical, el espacio principal del edificio, mientras que en una planta superior se dispondrian las estancias dedicadas a espacio de 
Todos estos edificios -asociados en la mayoría de los casos a palatia- constituidos por una única nave terminada en ábside y de planta estrictamente longitudinal, con cubierta a dos aguas y techumbre plana en madera, y precedida habitualmente por un nártex, constituyen el tipo predominante de basílica en los primeros decenios del s.IV, momento en el que la planta basilical atraviesa una fase de revitalización (KRAUTHEIMER, 1967: 125). Ello permite matizar los datos que a nivel estratigráfico ha aportado la excavación del conjunto de Cercadilla, de modo que, dentro del ámbito cronológico ya fijado para su construcción, habría que pensar que ésta se llevaría a cabo en el momento más avanzado, o sea, a principios del s. IV.

Por su parte, los edificios triconques constituyen un modelo muy difundido dentro de la arquitectura romana y aplicado durante un dilatado espacio de tiempo. Este diseño, de amplia funcionalidad, se emplea profusamente en época tardorromana en triclinia -asociados a stibadia- (18), palatia (19), mausolea (20) y termas -en especial caldaria- (21). A partir del s. IV su diseño se difunde también en la arquitectura cristiana apareciendo en baptisteria y martyria (22) para, sobre todo entre los siglos V y VI, hacerse común también en basílicas (23).

En lo que se refiere a la organización del espacio, el esquema seguido en Cercadilla entre plaza en exedra-aulas basilicales, es muy similar al que presentan algunos de los complejos palatinos arriba mencionados entre peristilo-aulas basilicales, todo ello manteniendo en las grandes aulas basilicales el eje de axialidad como elemento coordinador de los edificios. En el caso de Cercadilla el eje de simetría se establece en el aula central coincidiendo además con el acceso al recinto y, siguiendo los principios

habitación. En el caso de Cercadilla se puede observar que toda la planta conocida corresponde a grandes espacios de recepción, sin que de momento se pueda descartar que, al igual que ocurre en Meleda, existiese un piso superior, al menos en alguno de los edificios, donde se dispondrían los espacios de habitación.

(18) Aulas triconques usadas como triclinia (vid. LAVIN, 1962) las encontramos en villas como Patti Marina (VOZA, 1982:fig. I), en Sicilia, Ecija (GORGES, 1979:lám. XLVI.1) o la de Desenzano del Garda (ARSLAN, 1982:fig.61), en el Norte de Italia, todas del s.IV.

(19) Según Diggve (1941) una parte del palatium sacrum o santuario del palacio imperial estaba constituido por una serie de salas para las ceremonias donde el emperador-dios se mostraba. La sala principal de este palatium sacrum era la «basílica abierta" culminando el conjunto con el triclinium, aplicado en muchos casos a sala de audiencia o del trono donde el emperador se presentaba como un dios, en el ábside central -entendiendo éste como elemento glorificante- frente a la entrada, mientras que los laterales, posiblemente con funciones de acompañamiento o acogimiento, estarían ocupados por los herederos del trono o por otros miembros de la familia imperial, particularmente cercanos al emperador, que le acompañarían durante las ceremonias, o por altos funcionarios. La representación ceremonial en una trichora permitía la organización jerarquizada siguiendo esquemas ceremoniales similares al representado en el missorium de Teodosio conservado en la Real Academia de la Historia de Madrid (ARCE, 1988:169-189).

(20) Por ejemplo en Isola Sacra o en el Cimitile de Roma (ZOVATTO, 1965:10).

(21) Especialmente en las termas constantinianas de Tréveris (NIELSEN, 1990:72) y en las de Feriana en el Norte de Africa (ZOVATTO, 1965:17).

(22) Como martyrium lo encontramos en Concordia (FORLATI, 1960:fig.4) y con cierta frecuencia en el Norte de Africa, donde se encuentran los de Damous el Karita, Ksar Hellal o Bir Ftoucha (DUVAL-CINTAS, 1976:900-903).

(23) Aplicado a basílicas lo encontramos en la Natividad de Belén (TESTINI,1980:658), en la Trinidad de Lérins (TESTINI, 1980:657-660) y es muy común en la costa Este del Adriático en los siglos V y VI, manteniendo el esquema arquitectónico muy puro en las de Sutivan y Pridaga (CAMBI,1984:fig.4 y 8). 
de axialidad longitudinal, todos los edificios actualmente excavados en la zona Sur del pórtico se repetirán con toda probabilidad en la zona Norte, completando así la simetría del conjunto.

La disposición de los puntos focales se centra al interior del edificio, como es habitual (vid. DUVAL, 1978:44), creando un fuerte contraste entre el acceso al monumento -cerrado, torreado y sin perspectiva alguna- y el interior, en el que inmediatamente se abre un amplio campo de visión, potenciado por la forma semicircular del pórtico, en el que se perdería la vista entre los distintos edificios y accesos.

Por otra parte, a nivel conceptual el edificio de Cercadilla puede relacionarse con construcciones ya citadas como Piazza Armerina, el palacio de Galerio en Gamzigrad o el de Majencio en la vía Apia, coincidiendo además, con la tendencia que a partir de la tetrarquía mantiene la arquitectura palacial, que adopta una expresión estructural propia hasta alcanzar su cénit con el palacio de Constantinopla, donde se asumen todas las tendencias existentes. Algunos aspectos de esta arquitectura son comunes al complejo de Cercadilla y a todos los conjuntos palaciales, imperiales o no, reflejándose también en algunos casos en la arquitectura urbana de la época: concepción axial de la planta, simetría de las unidades arquitectónicas, cerramiento al exterior y proyección al interior con puntos focales internos y solidez constructiva mediante grandes masas murarias (PISANI-CALZA, 1976:149).

Así pues, en el estado actual de la investigación, la línea de trabajo establecida estriba en confirmar la hipótesis según la cual interpretamos el monumento de Cercadilla como un palatium (24) entendido más como centro administrativo, político y religioso que como lugar de residencia de un dominus o de un gran possesor.

El hallazgo de un conjunto monumental de las dimensiones y características arquitectónicas del aquí presentado adquiere unas connotaciones peculiares de cara al análisis histórico de Colonia Patricia Corduba, de la que tanto su posición política como su vida urbana durante el s. IV aparecen a nuestros ojos desdibujadas y no exentas de enormes lagunas históricas y arqueológicas. Córdoba se sitúa durante el s.IV a la altura de otras importantes ciudades de la Diócesis como Emerita, Tarraco o Caesaraugusta, y a nivel político mantiene la capitalidad de la Bética (25).

(24) Este término (CAGIANO, 1986:265-266; GIULIANO, 1965:850) como es bien sabido es el topónimo de la colina romana donde Augusto y sus sucesores situaron su residencia, designando en el alto imperio el lugar donde el Emperador reside y ejerce su autoridad. En el momento que la capitalidad se transfiere de Roma, surgen diversos palacios, aplicando el topónimo a diversas estructuras edilicias,, no indicando un tipo arquitectónico sino una patente de oficialidad, de nobleza y grandeza a determinados edificios, en virtud no de su estructura sino de quien los habita. Sobre todo a partir de la segunda mitad del s. III, con el aviso de las futuras invasiones, queda patente la insuficiencia administrativa del imperio, surge el descentramiento del poder y muchas ciudades periféricas acogen una corte de cesares o de augustos, en ambos casos afianzada mediante un importante aparato burocrático que necesita un alojamiento adecuado, y aparecen así palacios como los de Tréveris, Salónica o Constantinopla. El término llega a degenerarse, llegando a aplicarse a cualquier residencia investida de cierto carácter de interés público y de forma general a edificios suntuosos sin relación con su función.

(25) Los versos de Ausonio, en su referencia a la Diocesis Hispaniarum en momentos de la segunda mitad del s.IV dC. mencionan a Emerita como capital, a Bracara como ciudad rica, a Corduba y a Tarraco como ciudad 
La Diocesis Hispaniarum gozó durante el imperio de Constantino y sus sucesores de paz y prosperidad (Zosimo, III, 8.3), pasando la Baetica (26) de ser gobernada por un praesidialis a serlo por un consularis a mediados del s. IV dC. (27). Las fuentes recogen la referencia a Corduba como lugar donde el vicarius hispaniarum recibe la legislación, y en ocasiones tiene su lugar de residencia (ARCE, 1977-78 y 1986).

De época constantiniana son asimismo tres inscripciones cordobesas en las que se documenta la continuidad del culto imperial (28) y la presencia en Córdoba de un vicarius hispaniarum y de dos praesides de la Bética. Asimismo, se conoce que el comes hispaniarum Rufinus Octavianus se encontraba en Córdoba en el 317 dC. (Cod. Theod., 9.1.1.).

Creemos que ha de considerarse la posibilidad de que el centro político urbano se desplace desde el Foro Provincial a intramuros hacia un nuevo emplazamiento a extramuros, el conjunto monumental descubierto en Cercadilla. Es por esto que la pretendida decadencia de la ciudad basada en la amortización y desparición del espacio forense debe ponerse en duda y ver en ello no un debilitamiento de la estructura urbana sino un reforzamiento de ésta y un síntoma evidente de prosperidad urbana así como de su indudable vertebración en la nueva administración imperial. A principios del s. IV dC. se da una pérdida de identidad del foro provincial, materializado en la ocupación del espacio público por construcciones privadas de ámbito doméstico (VENTURA, 1991), coincidiendo asimismo con la erección de pedestales honoríficos dedicados por los gobernadores a emperadores del s.IV en el entorno del foro colonial (STYLOW, 1990: 279) (29). Creemos que este cambio físico del lugar representativo del poder imperial obedece asimismo a un cambio en la concepción y ejercicio de éste, que arranca desde las reformas de Galieno, pasando por los cambios ideológicos de Aureliano, la tetrarquía y definitivamente se reafirma en la monarquía constantiniana y el imperio cristiano.

Ha de tenerse en cuenta la posible vinculación del conjunto monumental con un officium imperial, posiblemente con el del gobemador provincial, en donde tendría su sede el praeses o el consularis Provinciae Baeticae, figura administrativa encargada de la recaudación, de la posta publica, de la supervisión de las obras públicas y de ejercer la función de juez ordinario. Por otra parte, la presencia del palatium de Cercadilla a extramuros y alejado $700 \mathrm{~m}$. del recinto amurallado de la ciudad no ha de verse

con potente fortaleza (AUS., Par., XV). La referencia a Corduba es significativa ya que supone su consideración como una de las ciudades de mayor importancia en la Hispania de la época así como un reflejo claro de su situación política preeminente.

(26) Aulus Caecina Tacitus es praeses Provinciae Baeticae a comienzos del gobierno constantiniano; del 312 al 324 encontramos en tal cargo a Octavius Rufus (JONES ET ALII, 1971; C.I.L., II, 2204); en el 337 encontramos a Egnatius Faustus (C.TH., 11.9.2).

(27) En el 353/57, se conoce la existencia de Decimius Germanianus, vir clarissimus consularis provinciae Baeticae.

(28) Encontramos como dedicantes al vicarius hispaniarum Q. Aeclanius Hermias y a los praesides de la Bética Egnatius Faustinus y Octavius Rufus.

(29) Decimus Germanianus, consularis de la Bética ofrece un epígrafe a Constancio II (RODRIGUEZ NEILA, 1988:504). 
exclusivamente como un intento de separar el poder del núcleo urbano, tendencia generalizada en los palacios tardorromanos (PISANI-CALZA, 1976:151), sino que posiblemente nos encontremos ante una zona monumental de la ciudad. Ello entroncaría con la posible existencia de un circo en sus cercanías, en concreto en los terrenos de la Facultad de Veterinaria, en donde, a través de las excavaciones realizadas en los años 30 y el estudio cartográfico, se observa la existencia de una anomalía paleotopográfica con forma de elipse y estructuras de gran entidad (30). No debe olvidarse en este aspecto la íntima relación circo/palacio en el mundo tardío, y su importancia ideológica y ceremonial (KRAUTHEIMER, 1987).

En otro orden de cosas, un fenómeno trascendental para la comprensión del mundo tardorromano, el cristianismo, debió tener en Córdoba una implantación temprana, siendo destacable la información referente a los primeros mártires cristianos cordobeses (SOTOMAYOR, 1979), en concreto nos referimos a los martirizados durante la persecución de la Tetrarquía iniciada a partir del 302 con la depuración del ejército, llevada a cabo por Maximiano bajo los designios de Galerio y Diocleciano (PASQUALINI, 1976: 135-137) y ejecutada por el hipotético praefecto Dion o praeses Datianus (SIMONET, 1924; GAIFIER, 1954; JONES ET ALII, 1980), Prudencio nos transmite sus nombres Acisclo y Zoilo (Prud., Perist., I) (31). Un elemento de enorme interés, relacionado con la presencia del cristianismo en Córdoba, es la importación de sarcófagos romanocristianos de época constantiniana, lo cual nos informa acerca de la cristianización de las oligarquías locales y quizás su relación con las corrientes cristianas de Roma (SOTOMAYOR, 1975) (32).

El personaje de mayor trascendencia histórica y religiosa de la Corduba del s. IV dC. es sin duda el Obispo Osio, quien ejerci6 su cargo desde el 294 al 357. Fue elegido obispo

(30) Samuel de los Santos (1955:10) se refiere a este hallazgo: "...en la Facultad de Veterinaria, se hallaron, en 1934, cimientos y muros colosales de sillares almohadillados, que sugieren la existencia aquí de un gran edificio público romano, quizá el Stadium".

(31) En nuestra opinión la reutilización del aula triconque Norte como lugar de culto cristiano puede ponerse en relación con el culto martirial y tener sus precedentes inmediatos en los martiria de Sta. Eulalia en Emerita, de S. Emeterio y Celedonio en Calagurris y de Sta. Eulalia en Barcino. El inicio de su utilización como basílica cristiana se remonta posiblemente a fines del s. V d.C., cuando en un ambiente conflictivo los obispos ejercen la representación de la ciudad. A comienzos del s. V dC. las reliquias de los santos se utilizan como protectoras de la ciudad ante los agresores y su intercesión milagrosa es usada como elemento propagandístico, así encontramos paralelos al culto y exaltación de las reliquias de San Acisclo en otros lugares de Hispania como Mérida con las de Sta. Eulalia (Prud., Per., III) y Zaragoza con las de San Vicente y los dieciocho mártires (Prud., Per., IV). Es más, ello está corroborado por las fuentes ya que el culto a los santos en Córdoba era destacado a comienzos del s.V. En concreto nos referimos a la alabanza realizada en un Concilio por Theodosio del obispo Gregorio por la celebración en Córdoba de las fiestas natalicias de los mártires, noticia transmitida por el autor del s.IX Walafridus Strabo (RODRIGUEZ NEILA, 1988:514).

(32) De la primera mitad del s.IV se conservan cuatro ejemplares:

315-320: sarcófago de Belalcázar: Daniel en el foso de los leones.

330-335: sarcófrago columnado, con escenas del antiguo y nuevo testamento, de la Huerta de San Rafael.

315-350: Frag. de sarcófrago constantiniano de la mezquita. Sarcófago columnado de la Ermita de los santos mártires.

Hemos de destacar la existencia de dos nuevos ejemplares en estudio, uno de ellos localizado en las cercanías del yacimiento de Cercadilla. 
de Córdoba y consagrado por el arzobispo romano (33). Sufrió los efectos de la persecución de Maximiano, durante la que realizó confesión de fe (34). Participa en el Concilio de Elbira (305-10) (35) como obispo de Córdoba. En el 313 aparece comisionado por el emperador Constantino para el reparto de subvenciones entre algunas comunidades cristianas norteafricanas. Es posible que desde este momento o en fechas inmediatamente anteriores a ésta (36) sea cuando Osio adquiera una particular relevancia como consejero personal e instructor religioso del emperador, llegando en ocasiones a ejercer funciones de delegado o agente imperial en cuestiones eclesiásticas. La influencia de Osio en el emperador es decisiva favoreciendo el hecho de que los pasos de éste hacia el cristianismo estuviesen también dirigidos a la reunificación del Imperio. Posiblemente se encuentre en Córdoba entre el 313 y el 325, año en que preside el Concilio de Nicea, actuando como representante del emperador -anteriormente había sido enviado con una misiva imperial a Alejandría pero Arrio no cedió en sus postulados-. Posiblemente desde el 325 al 343, año en que acude al Concilio de Sárdica, se encuentre en Córdoba (FERNANDEZ UBIÑA, 1991:50-52). Pudo estar asimimo en la ciudad desde el 343 al 353, fecha en la que es obligado a ir a Milán por Constancio para que suscribiese la acusación contra S. Atanasio. Volvió a Córdoba y recibió presiones de Constancio para que cediera al arrianismo, siendo confinado en Sirmio entre los años 356-357. Cabe la posibilidad de que la presencia de un personaje de la importancia y prestigio de Osio en la Córdoba constantiniana se relacione de forma más o menos directa con la fuerte transformación urbana que representa el palacio de Cercadilla, quizás como proyección en su sede episcopal del papel desempeñado junto al emperador.

\section{Addenda}

Desde la redacción de este trabajo -Enero de 1992- hasta su publicación -Septiembre del mismo año-, han continuado los trabajos de campo en el yacimiento de Cercadilla -actualmente ocupado en gran parte por las obras de la futura estación de ferrocarrilhasta concluir el pasado mes de Mayo, momento en el que finalizo la segunda fase de excavación. Como consecuencia de esta labor ha aumentado considerablemente el volumen de información en torno al yacimiento, de modo que la planimetría se ha visto completada por nuevos edificios que siguen organizándose en torno al portico semicir-

(33) Mox omnibus refulgens virtutibus, et miraculis exornatus, a romano archiepiscopo episcopus urbis Cordubae consecratus, (FOREZ, 1901).

(34) Carta de Osio a Constancio: "Ego confessionis munus explevi, primum cum persecutio moveretus ab avo tuo Maximiano"; Eusebio Cesariense (de la vida de Constantino, II, 63) dice que se hallaba ennoblecido con la confesión de fe; en el Concilio Sardicense, Carta dirigida a todos los obispos, se ologia a Osio por la confesión; Nicephoro $(8,14)$ al referirse a los que asistieron al Concilio de Nicea menciona que el obispo Osio de Córdoba mantenía señales de los tormentos por su confesión.

(35) Firma en undécimo lugar junto al presbítero Julián (ORLANDIS-RAMOS, 1986:31).

(36) En el concilio de Arlés, celebrado en el $314 \mathrm{dC}$., es acusado por los donatistas de ser el principal instigador de la política imperial contra ellos. 
cular, ocupando algunos de los espacios en los que antes no contábamos con dato alguno; además, en la zona Norte, la mejor conservada, se han localizado vestigios de la decoración arquitectónica del monumento constituidos por pavimentos musivos, estucos decorados y al menos un fuste de columna. Por otra parte, en el aula triconque Norte se ha localizado el sello del obispo Samson, que reafirma lo hasta ahora expuesto en torno a la Basílica de San Acisclo.

En los próximos meses se iniciará una nueva fase de trabajo, en este caso de laboratorio, cuyo objeto será el estudio de la información generada hasta ahora por el yacimiento, cuyos resultados esperamos ofrecer en futuros trabajos.

\section{Bibliografía}

ARCE, J. (1977-78): " Retratos tardorromanos de Hispania: la evidencia epigráfica", A.Esp.A 50-51.

- (1986): El último siglo de la España romana (284-409), Madrid.

- (1988): España entre el mundo antiguo y el mundo medieval, Madrid.

ARJONA CASTRO, A. (1982): Anales de Córdoba musulmana (711-1008), Córdoba. ARSLAN, E.A. (1982): Lombardia, Itinerari Archaelogichi 9, Roma.

BEDON, R.; CHEVALIER, R. y PINON, P. (1988): Architécture et urbanisme en Gaule Romaine, París.

BEK, L. (1983): "'Questiones Convivales. The Idea of the Triclinium and the Staging of Convivial Ceremony from Rome to Byzantium", Analecta Romana XII, 81-107.

CAGIANO DE AZEVEDO, M. (1977): “I palazzi tardoantichi e altomediavali", Atti XVI Congr. St. Archit., 303-318.

- (1978): “I palatia imperiali di Treveri, Milano e Ravenna”, 25 Corso di Cultura sull' arte Ravennate e Bizzantina, Ravena, 33-44.

- (1986a): "Problemi e aspetti dell'architettura fra Teodosio e Gregorio Magno", Casa, cittd e campagna nell Tardo Antico e nell' Alto Medioevo, Galatina (Lecce), 241-263.

- (1986b): “I palaci Tardoantichi e Altomedievali”, Casa, città e campagna nell Tardo Antico e nell' Alto Medioevo, Galatia (Lecce), 265-277.

- (1986c): “Il palatium di Porto Palazzo a Meleda"', Casa, città e campagna nell Tardo Antico e nell' Alto Medioevo, Galatina (Lecce), 301-311.

CAMBI, N. (1984): "Triconch churches on the eastem Adriatic", $X$ Congres International d'Archeologie Chretienne, II, Vaticano, 45-54.

CARANDINI, A.; RICCI, A. y VOS, M. DE (1982): Filosofiana: La villa di Piazza Armerina. Imagine di un aristocratico romano al tempo di Constantino, Palermo.

CLERQ, V. C. DE (1954): Ossius of Cordova, Washington.

COLINI, A.M. (1955): “Horti, Spei Veteris, Palatium Sessorianum", Atti della Pontificia Academia Romana di Archeologia, Memorie 8.3, 137 ss. 
DAREGGI, G. (1990): "Le santuaire de Caelestis a Thugga: un temoignage de l'ideologie imperiale de l'époque des Sévres", Cartage et son territoirie dans l' Antiquité. Histoire et Archéologie de l'Afrique du nord. Actes du IV Colloque International, París, 199-213.

DUVAL, N. (1965): ' 'La représentation du palais dans l'art du Bas Empire et du Haut Moyen Age d'aprs le Psautier d'Utrech", Cah. Arch. 15, 207-254.

- (1978): “Comment reconnaitre un palais impérial ou royal? Ravenne et Piazza Armerina”, Feliz Ravenna CXV, 27-62.

DUVAL, H. y CINTAS, J. (1976): "Le martyrium de Cincavi et les martyria triconques et tetraconques en Africa". MEFR 88, 853-927.

DUYURAN (1952): "First Report on the Excavatios on the Site of the New Palace of Justice at Istambul”, Istambul arkeoloji Muzeleri yilligi 5, 23-38.

- (1953): "Second Report on the Excavations on the Site of the new Palace of Justice at Istambul", Istambul arkeoloji Muzeleri Ylligi, 6, 74-80.

DYGGVE, E. (1941): Ravennatum palatium sacrum. La basilica ipetrale per ceremonie. Studi sull' architetura dei palazzi della tarda antichità, Copenhague.

- (1959): “'Intorno al palazzo sull'isola di Meleda”, Palladio 9, 19-26.

FERNANDEZ UBIÑA, J. (1991): “Aristocracia provincial y cristianismo en la Bética del s. IV”, en GONZALEZ ROMAN, C. (ed.) La Bética en su problemática histórica, Granada, 31-62.

FLOREZ, E. (1901): España Sagrada. Theatro Geographico-Histórico de la Iglesia de España, T.X, Madrid.

FORLATI, B. (1960): "Il sepulcreto paleocristiano di Concordia Sagittaria”, Cah. Arch. 11, 251-255.

FOUET, G. (1983): La villa gallo-romaine de Montmaurin, París.

GAIFIER, B. DE (1954): “'Sub Datiano praeside”, A.B. 72, 278 ss.

GALVEZ, R. (1924): "Un documento inestimable para la historia de Córdoba. El calendario mozárabe de Recemundo”, B.R.A.C. 9, 237-269.

GARCIA RODRIGUEZ, C. (1966): El culto de los santos en la España romana y visigoda, Madrid 1966.

GIULIANO, A. (1965): “Palazzo", E.A.A. V, 850 ss.

GORGES, J.G. (1979): Les villas hispano-romaines. Inventaire et problématique archéologique, París.

GUILLEN, J. (ed.) (1950): Obras completas de Aurelio Prudencio, Madrid.

IBAÑEZ CASTRO, A. (1983): Córdoba hispano-romana, Córdoba.

JONES, A.H.M.; MARTINDALE, J. y MORRIS, J (1980): The Prosopograhy of the Later Roman Empire (395-527), Cambridge.

KRAUTHEIMER, R. (1967): "The Constantinian Basilica", Dumbarton Oaks Papers XXI, 115-140.

- (1987): Tre capitali cristiane, topografia e politica, Torino. 
LAVIN, I. (1962): " The House of the Lord: Aspects of the Role of Palace triclinia in the Architecture of Late Antiquity and in the Early Middle Age"', Art Bulletin 44, 1-27.

MARTIN, R. (1972): Les cryptoportiques dans l' architécture romaine. Roma.

Mc KAY, D.G. (1975): Houses, Villas and Palaces in the Roman world, Londres.

MIELSCH, H. (1987): Die römische villa, Munich.

NAVASCUES, J.M. DE (1922): "Interesantísimo hallazgo de una bóveda romana en el camino de Sevilla", B.R.A.C. I, 87-92.

NIELSEN, I. (1990): Thermae et balnea, Aarhus.

ORLANDIS, J. y RAMOS-LISSON, D. (1986): Historia de los concilios de la España romana y visigoda, Pamplona.

PASQUALINI, A. (1976): Massimiano Herculis, Roma.

PISANI SARTORIO, G. y CALZA, R. (1976): La villa di Massenzio sulla via Appia, Roma.

RAKOB, F. (1974): “Das Quellenheiligtum in Zaghouan und die römische Wasserleitung nach Karthago", R.M. 81, 41-89.

RAMIREZ DE ARELlANO Y GUTIERREZ, T. (1973): Paseos por Córdoba, Córdoba/León.

REUSCH, W. y MYLIUS, H. (1949): “'Zur Frage der römischen Apsiden-Grossbauten im Moselraum', Trierer Zeitschriff 18, 194 ss.

RODRIGUEZ NEILA, J.F. (1988): Historia de Córdoba, del amanecer prehistórico al ocaso visigodo, Cordoba.

SANCHEZ DE FERIA, B. (1772): Palestra Sagrada o memorial de Santos de Córdoba, Córdoba.

SANTOS GENER, S. DE LOS (1955): Memoria de excavaciones del Plan Nacional realizadas en Córdoba (1948-1950). Informes y Memorias de la C.G.E.A. n³1, Madrid.

SOTOMAYOR, M. (1975): Sarcófagos romanocristianos de España, Granada.

SOTOMAYOR, M. (1979): Historia de la Iglesia en España. I. España romana y visigoda, Madrid.

SREJOVIC, D.; LALOVIC, A. y JANCOVIC, D. (1983): Gamzigrad. Kasnoanticki Carski Dvorak, Belgrado.

STYLOW A.U. (1990): “Apuntes sobre el urbanismo de la Corduba romana”, en TRILLMICH, W. y ZANKER, P. (eds.), Stadtbild und Ideologie. Die Monumentalisierung hispanischer Städte zwischen Republik und Kaiserzeit, Munchen.

SWOBODA, K.M. (1924): Römische und romanische Paläste, Wien.

TESTINI, P. (1980): Arqueologia Cristiana, Bari.

VENTURA, A. (1991): "'Resultados del seguimiento arqueologico en el solar de C/ Angel de Saavedra n 10, Córdoba”, A.A.C. 2, 253-290.

VERZONE, P. (1976): “'La distribuzione dei palazzi imperiali di Roma e di Ravenna e la ristrutturazione del palazzo Lateranense nel IX secolo nei raporti con quello di Constantinopli", Roma e l'età Carolingia, Roma, 39-54. 
VIVES, J.; MARIN, T. y MARTINEZ, G. (1963): Concilios visigóticos e hispanorromanos, Barcelona-Madrid.

VOZA, G. (1982): "Le ville romane del Tellaro e di Patti in Sicilia e il problema dei rapporti con l'Africa”, 150-Jahr Feier DAI Rom, Mainz, 202-209.

ZOVATTO, P. L. (1965): “'Origine e significato della Trichora-Martyrium l'esempio di Concordia”, Palladio 15, 7-34. 


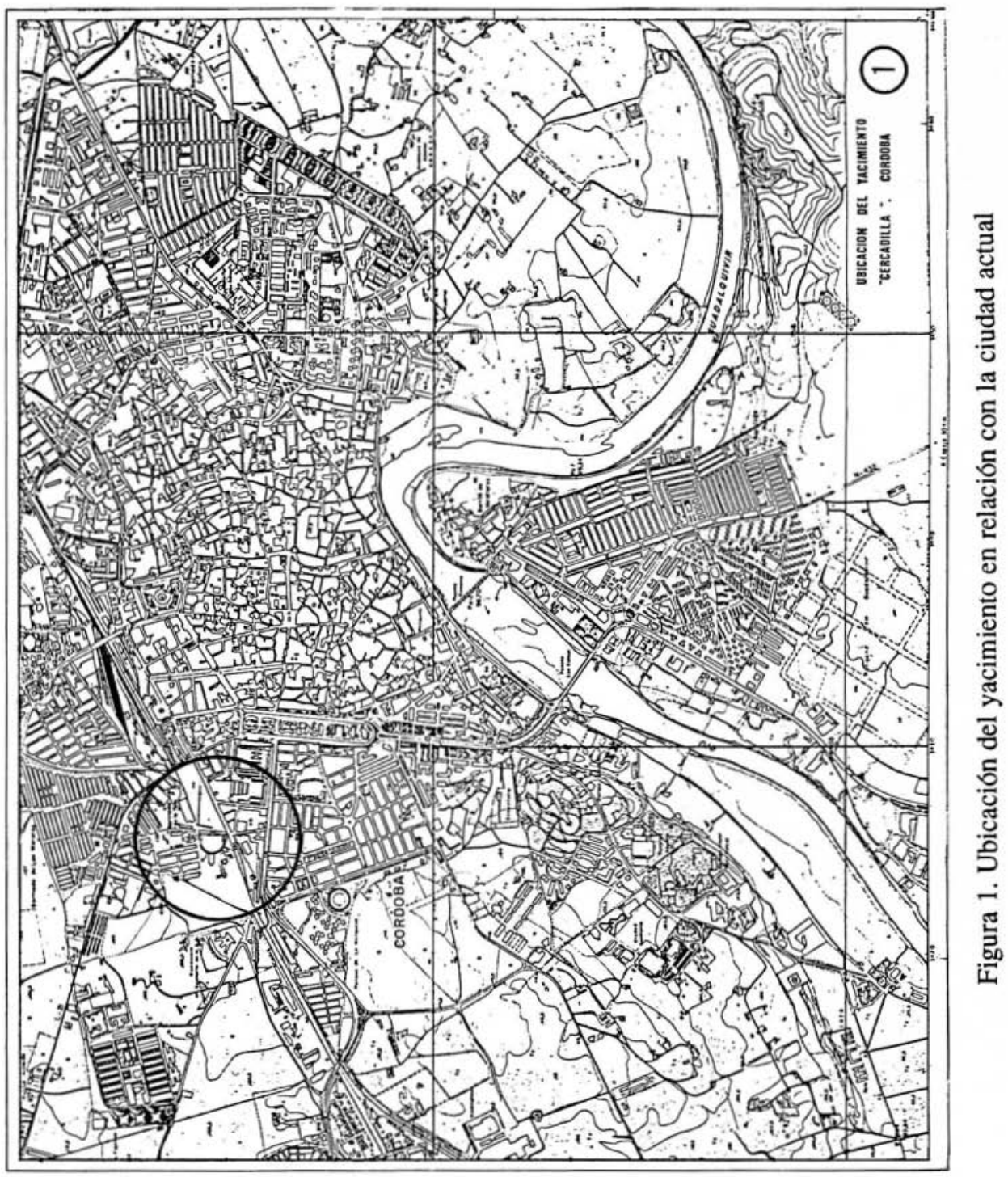




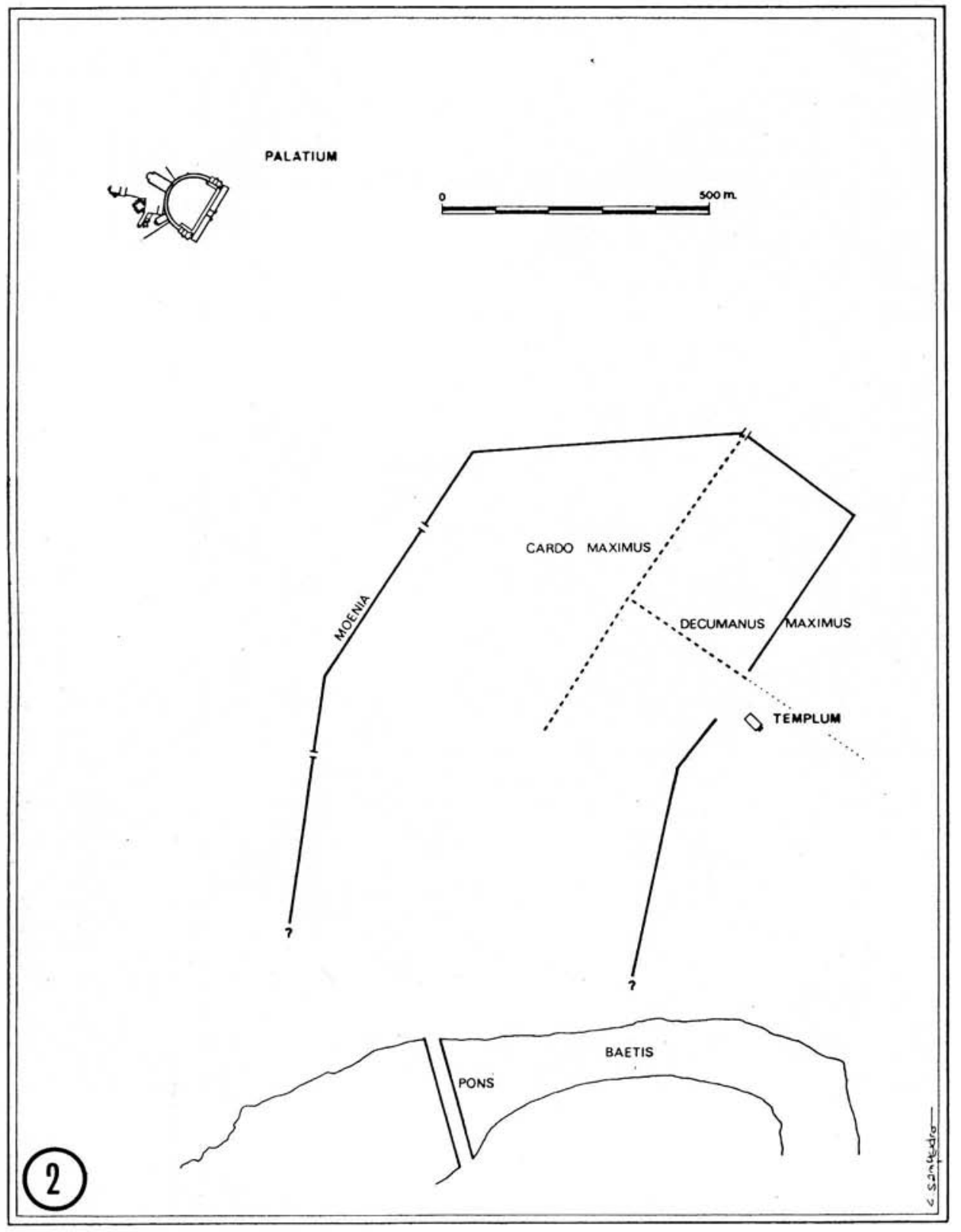

Figura 2. Ubicación del palatium de Cercadilla con respecto al recinto amurallado. (Plano de la ciudad según Stylow). 


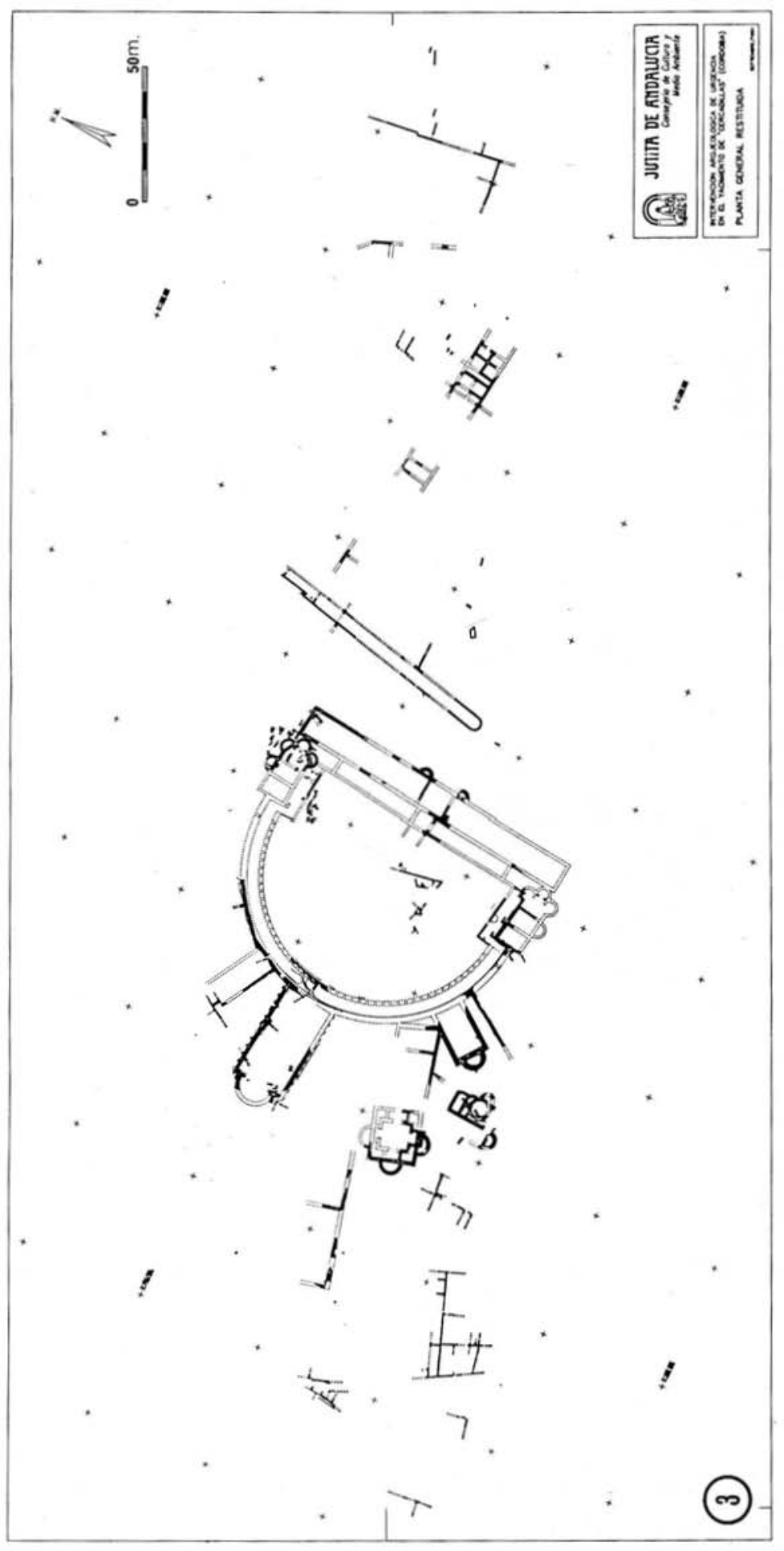

苛 


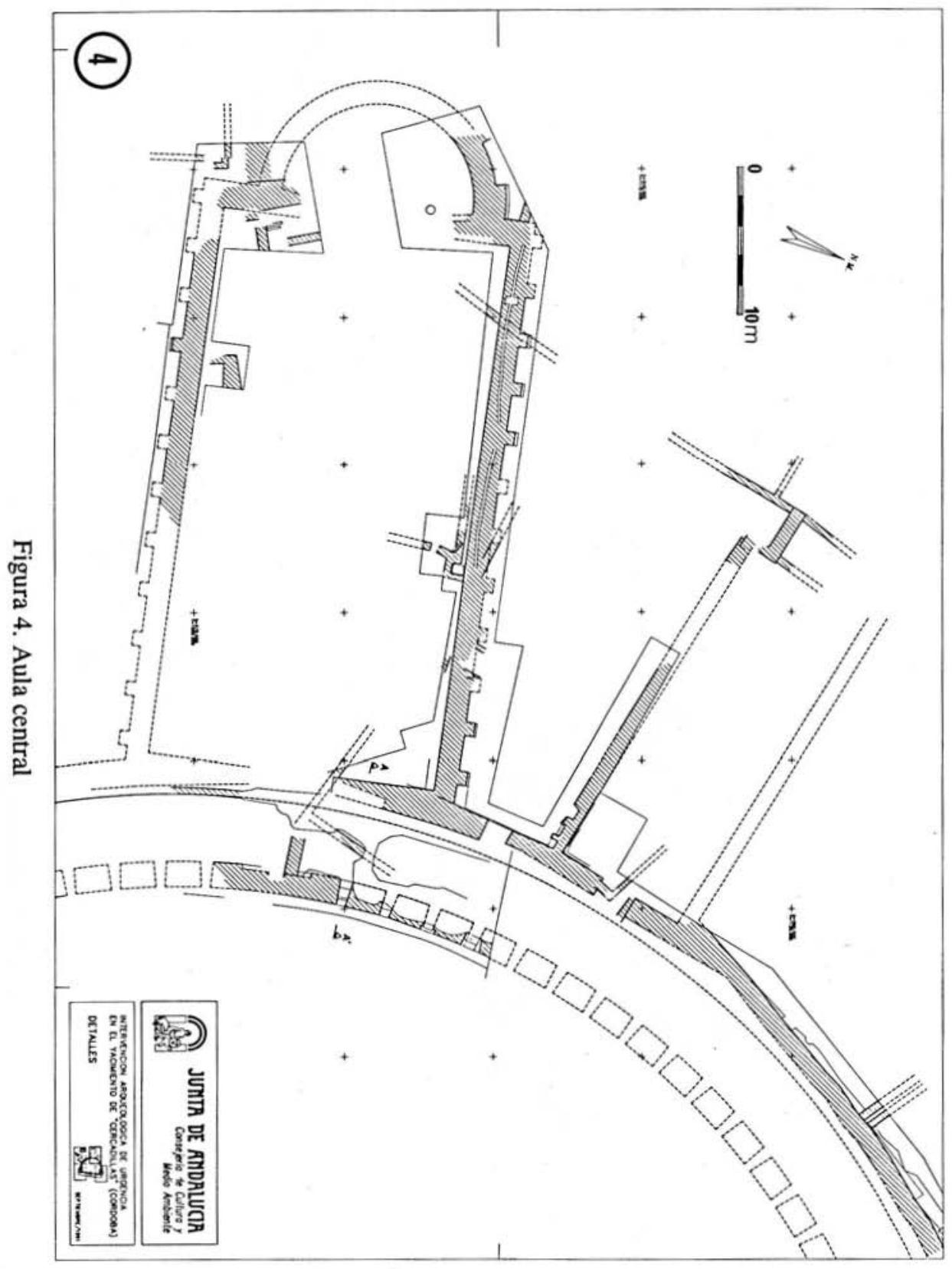




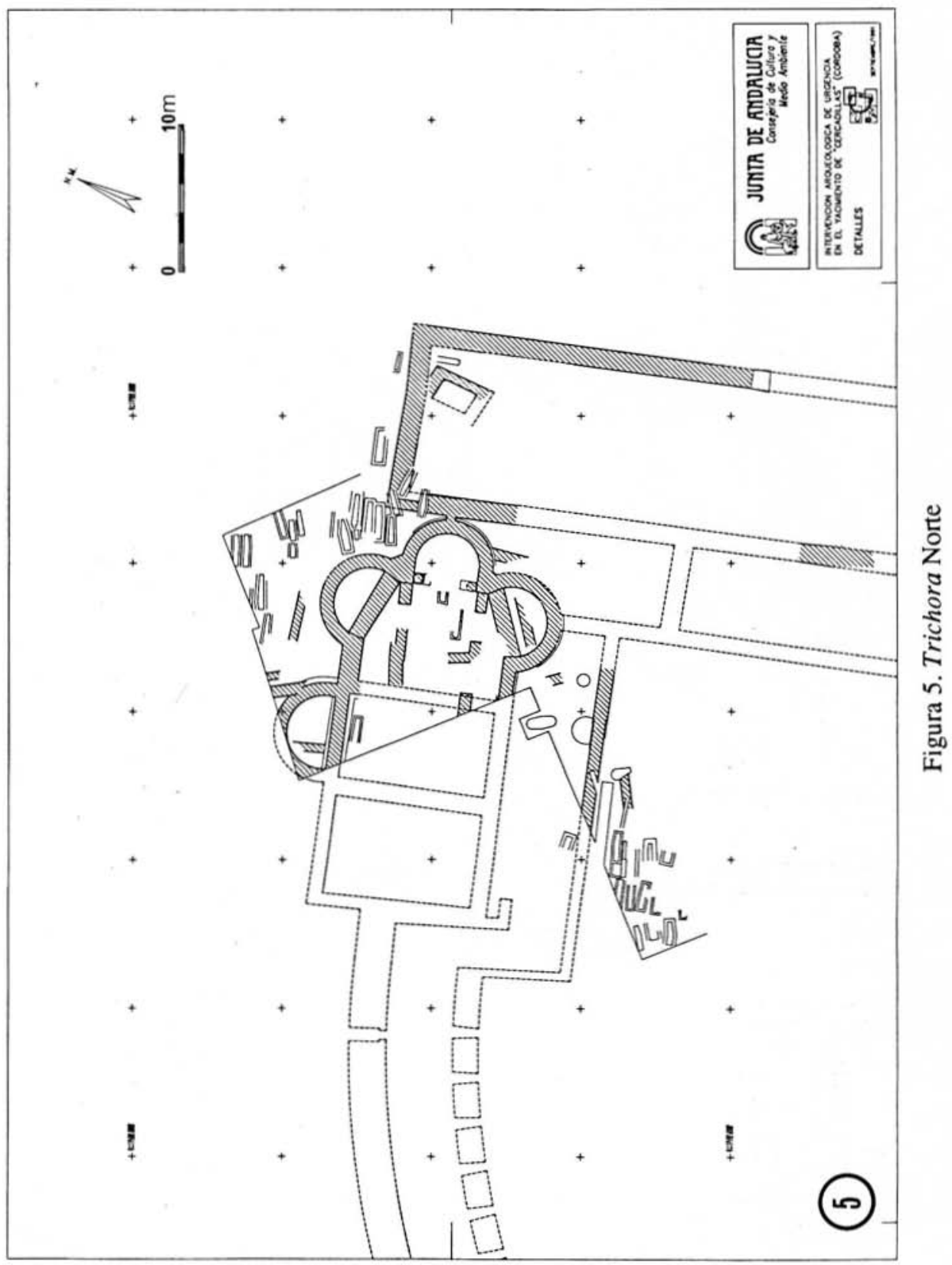




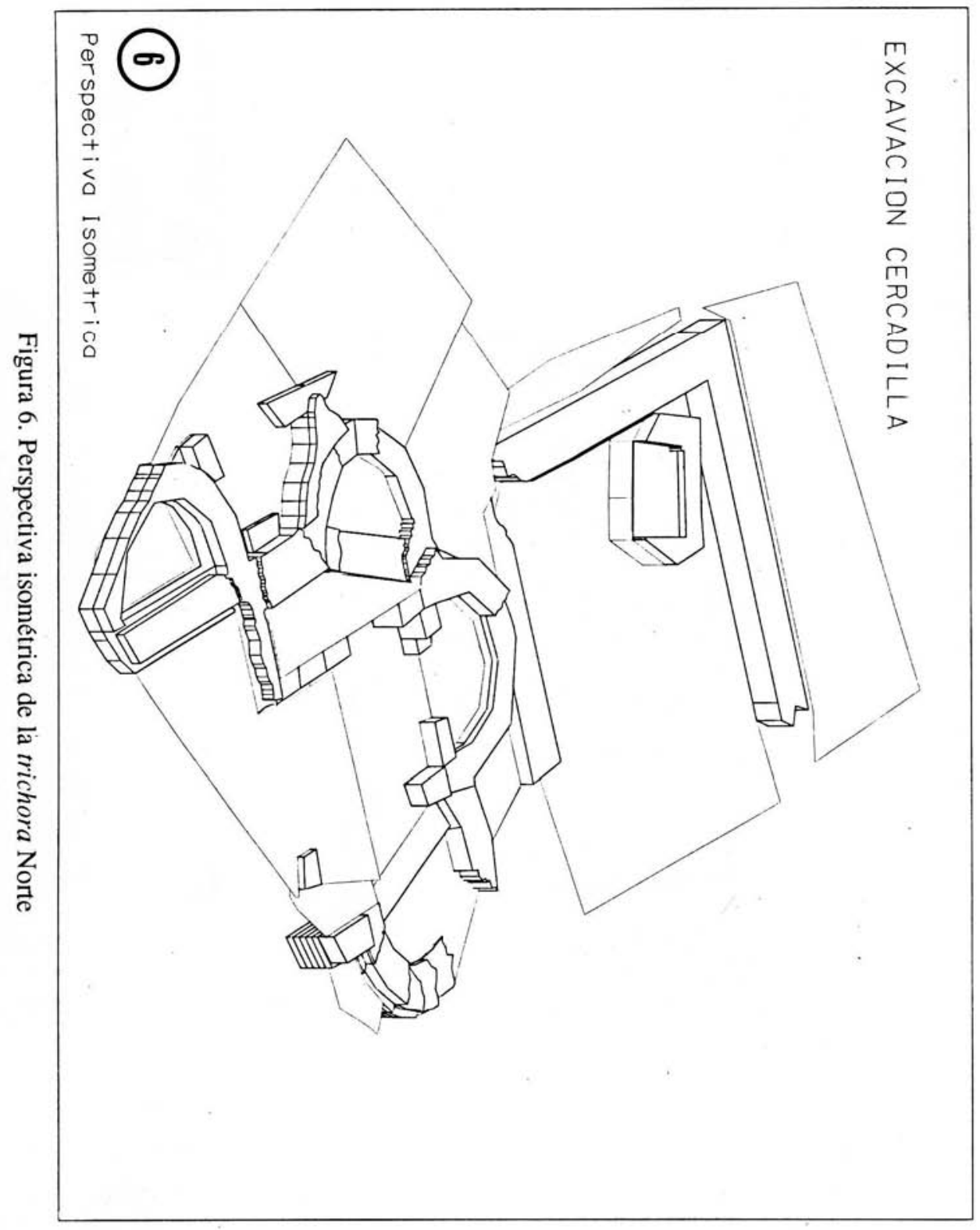




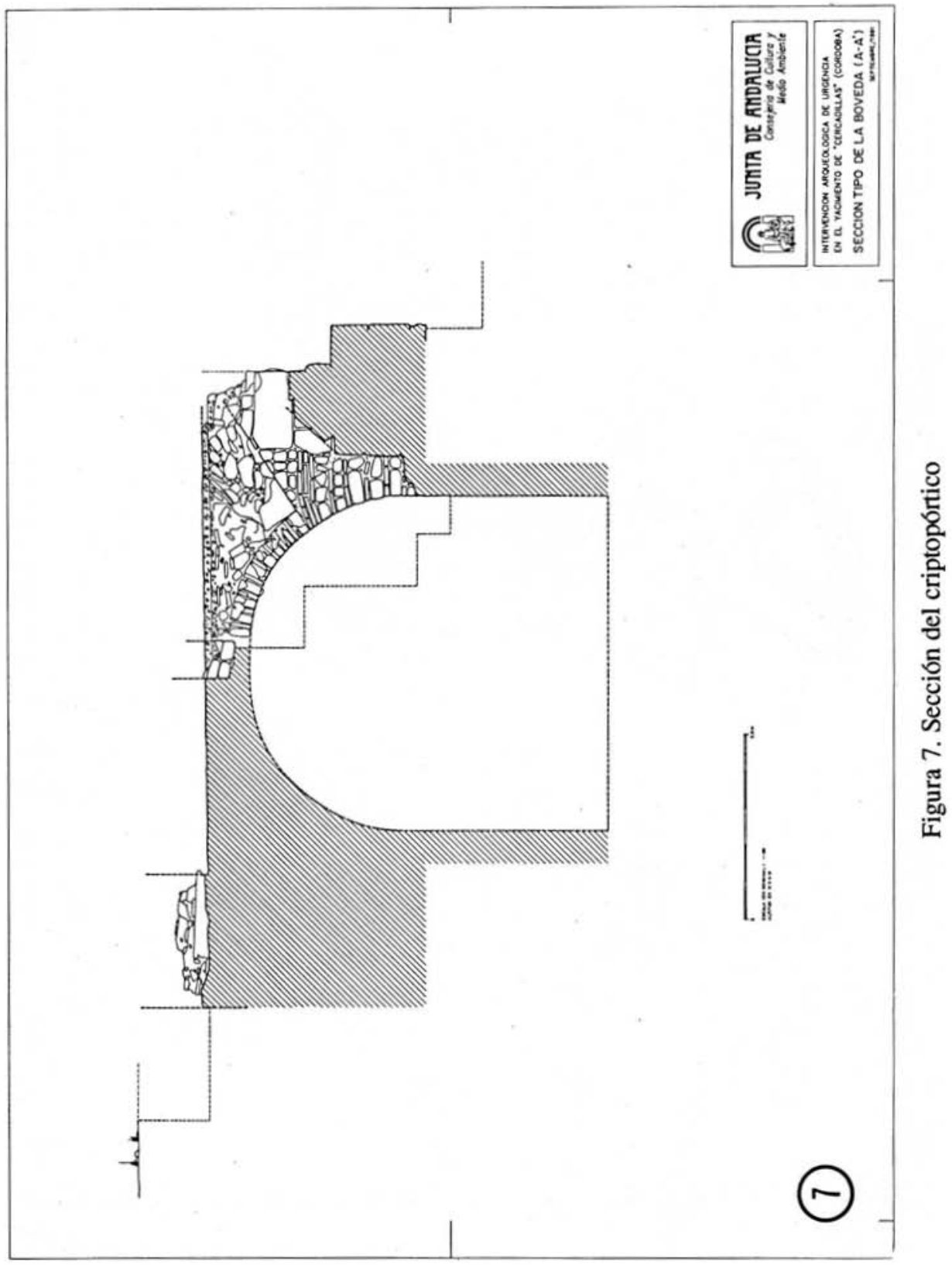




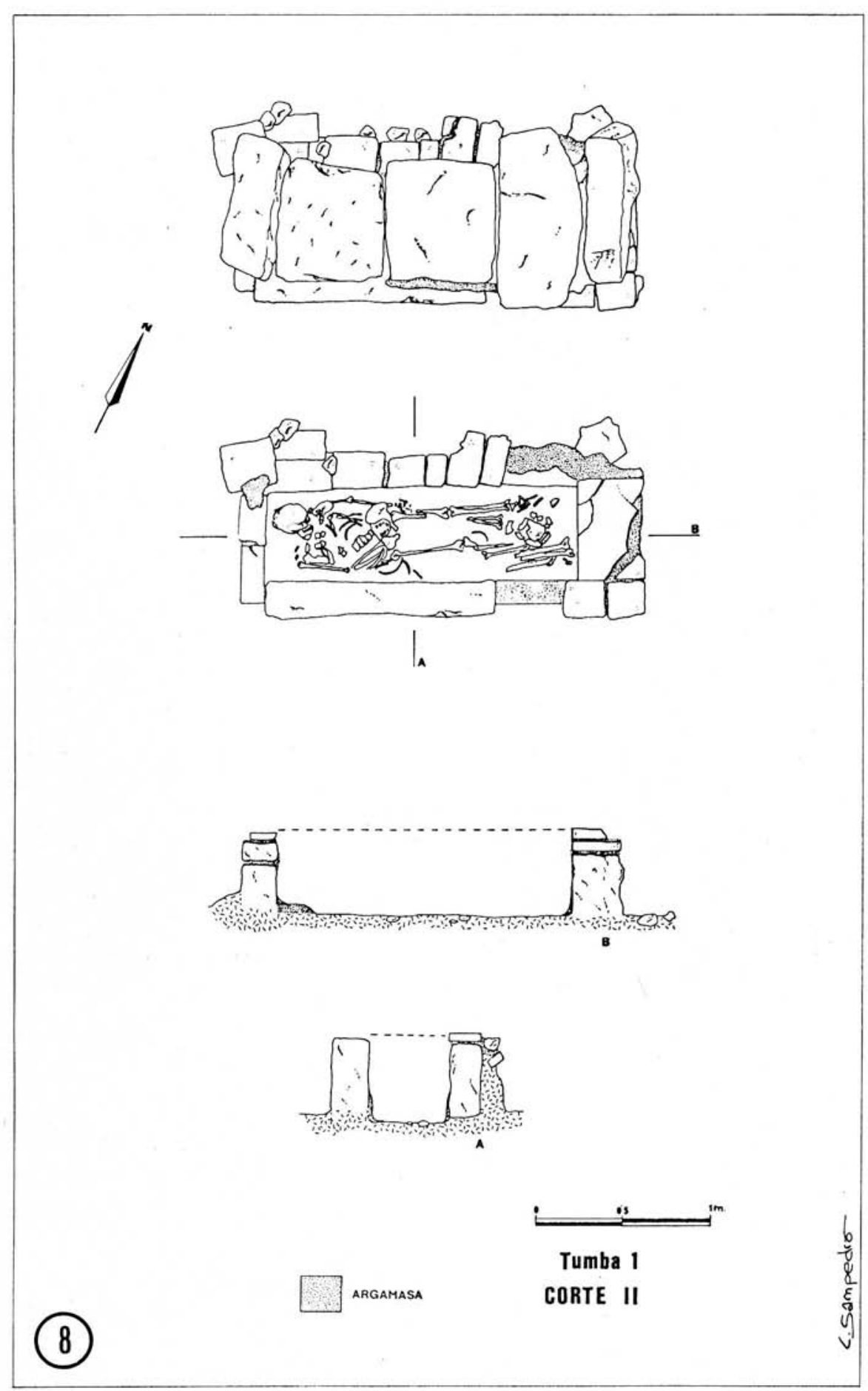

Figura 8. Tumba 1 (CER'91/corte II) 


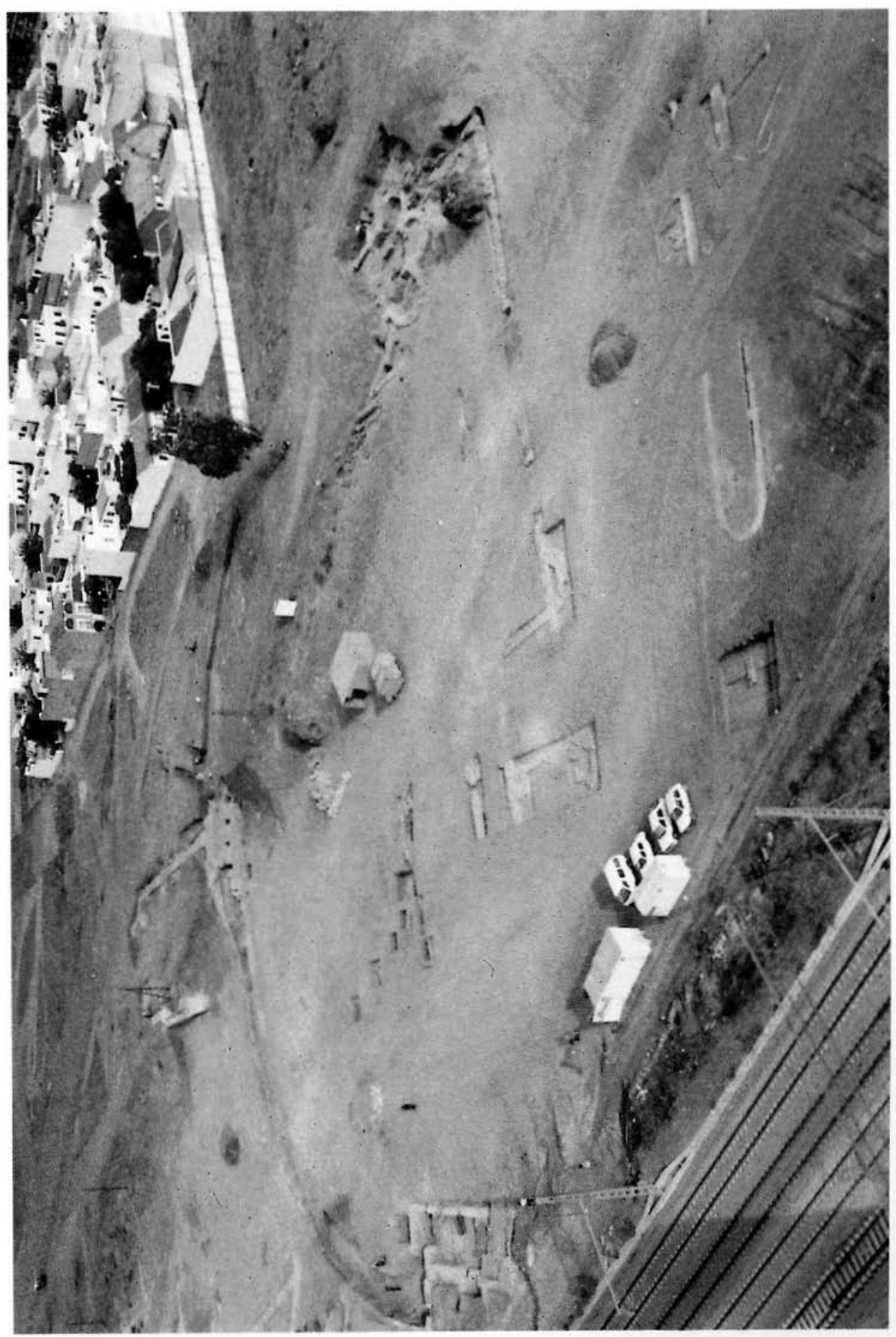

Lámina 1. Panorámica del palatium 


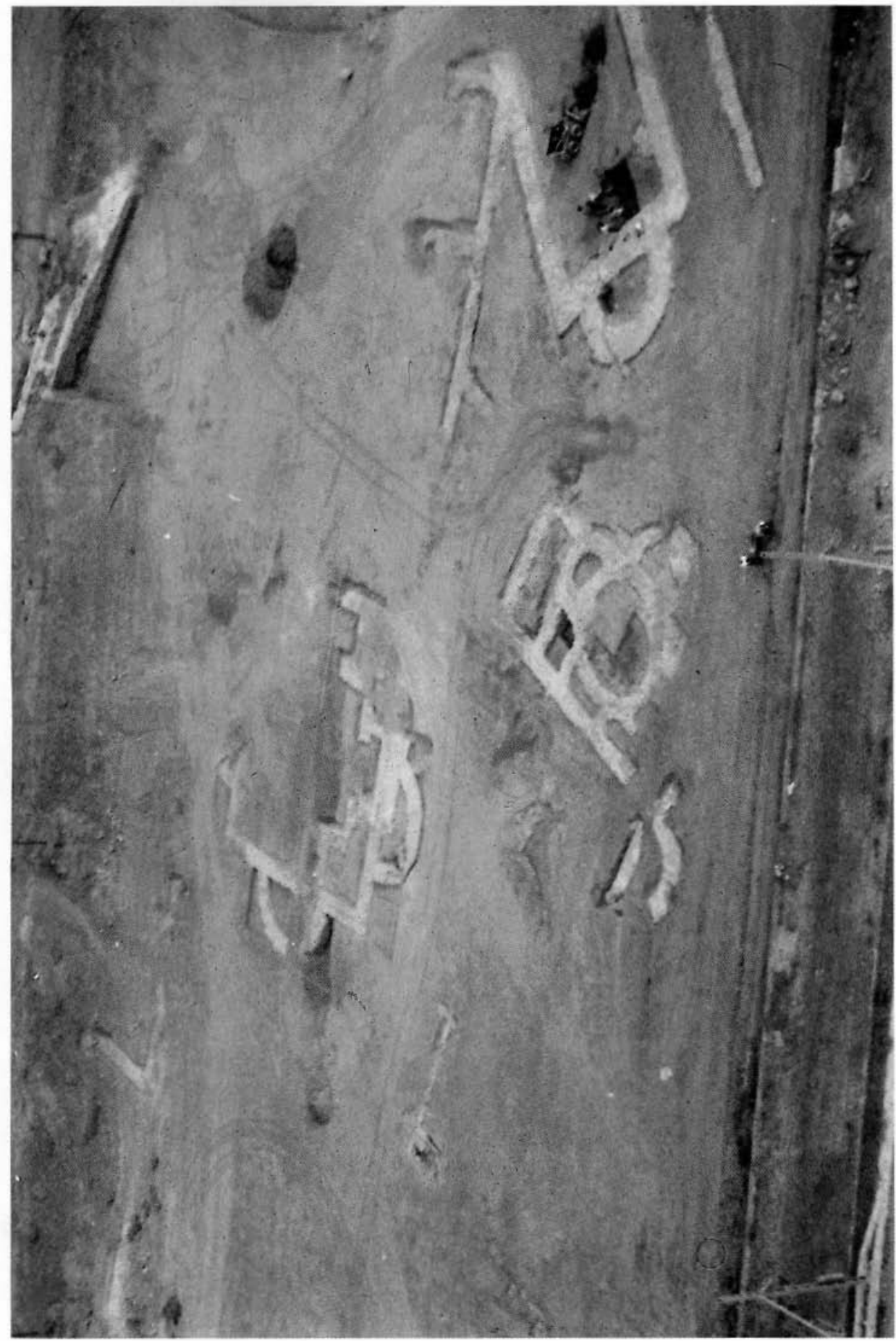

Lámina 2. Sector Oeste del yacimiento

396Grupo de investigación P.A.I. HUM 236 | http://www.arqueocordoba.com/publ/anales.htm --- 


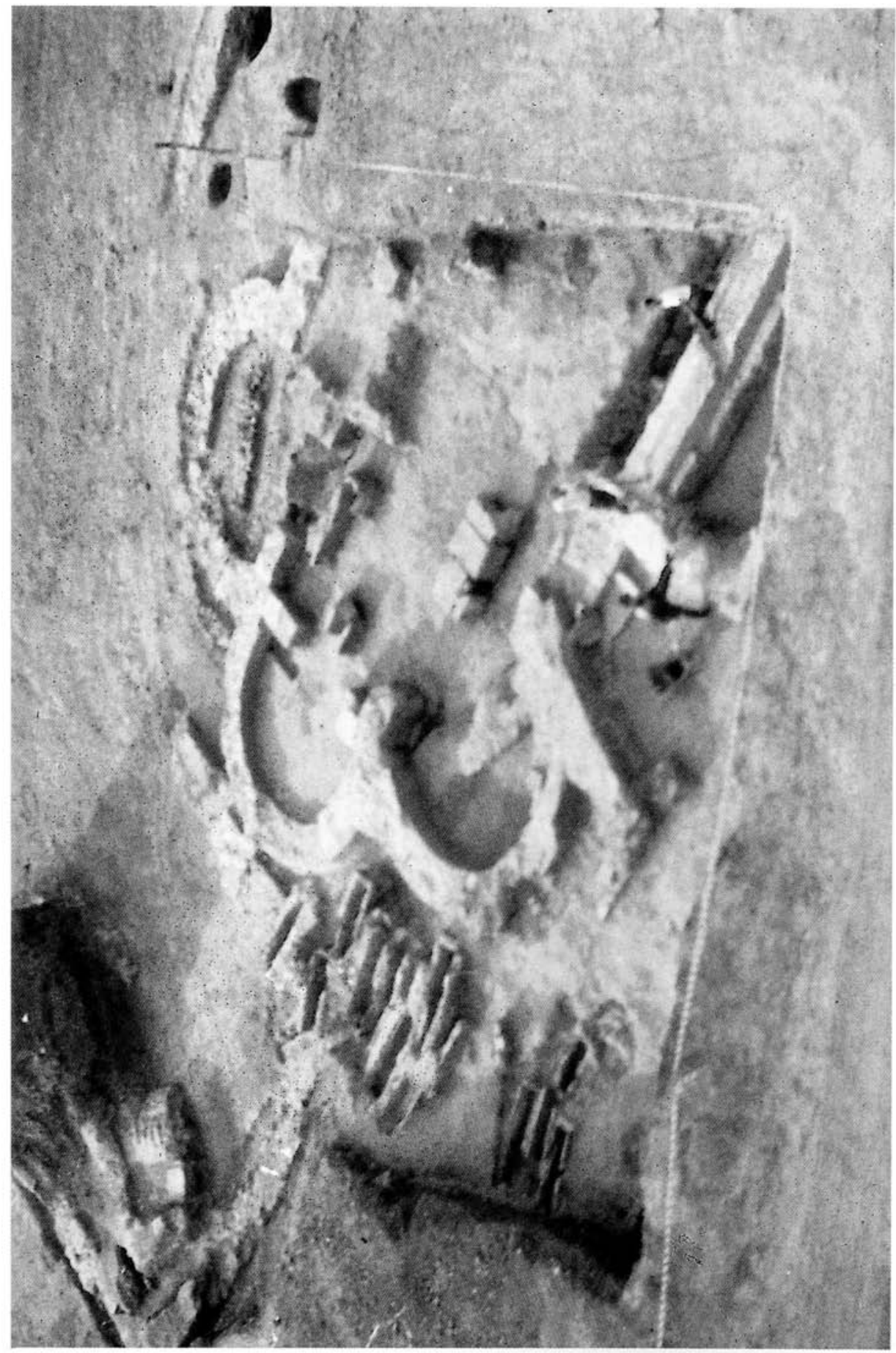

Lámina 3. Trichora Norte 

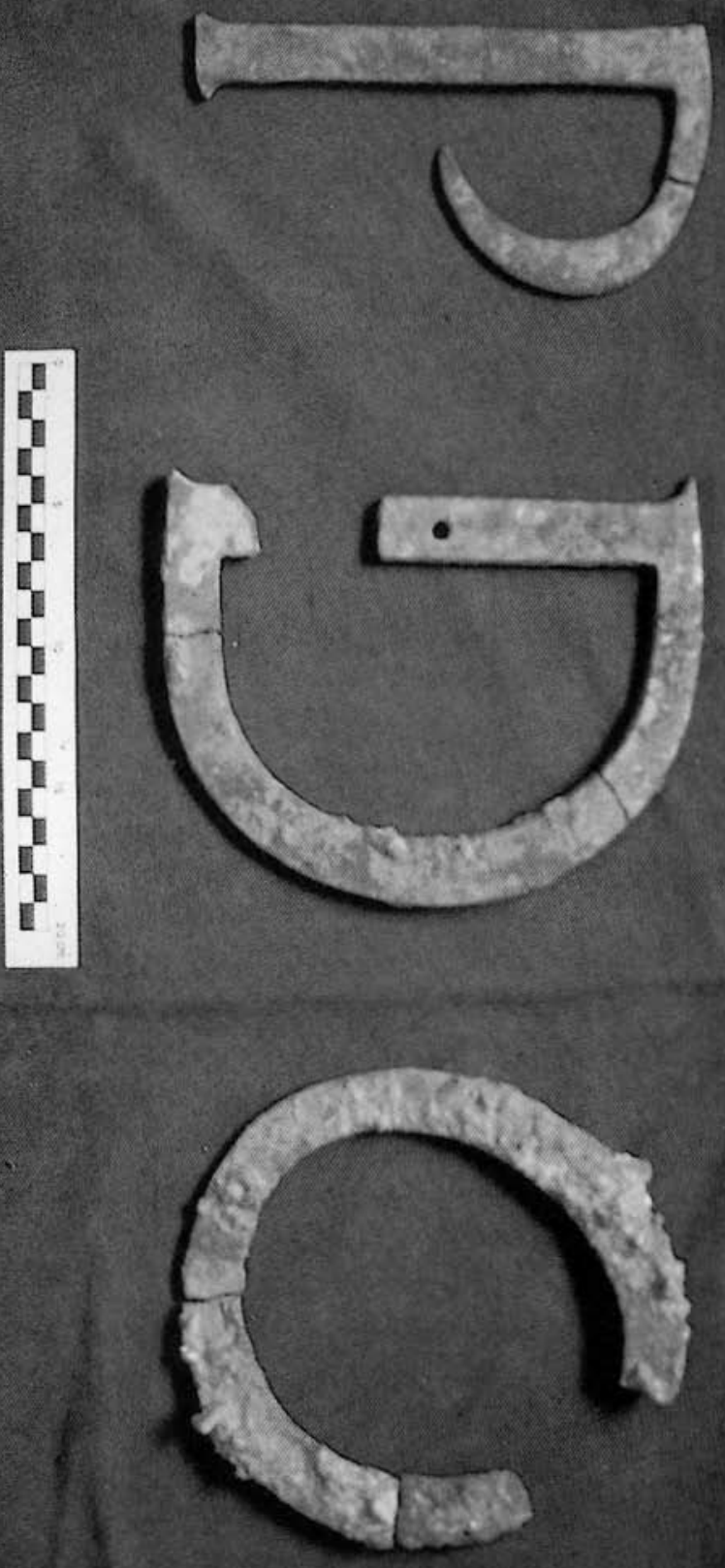

Lámina 4. Letras de bronce dorado localizadas en el interior del criptopórtico 